\title{
Article \\ Facile Method by Bentonite Treated with Heat and Acid to Enhance Pesticide Adsorption
}

\author{
Chutima Pluangklang and Kunwadee Rangsriwatananon *
}

check for updates

Citation: Pluangklang, C:

Rangsriwatananon, K. Facile Method by Bentonite Treated with Heat and Acid to Enhance Pesticide Adsorption. Appl. Sci. 2021, 11, 5147. https:// doi.org/10.3390/app11115147

Academic Editor: Francisco José Alguacil

Received: 23 April 2021

Accepted: 27 May 2021

Published: 1 June 2021

Publisher's Note: MDPI stays neutral with regard to jurisdictional claims in published maps and institutional affiliations.

Copyright: (c) 2021 by the authors. Licensee MDPI, Basel, Switzerland. This article is an open access article distributed under the terms and conditions of the Creative Commons Attribution (CC BY) license (https:/ / creativecommons.org/licenses/by/ $4.0 /)$.
School of Chemistry, Institute of Science, Suranaree University of Technology, NakhonRatchasima 30000, Thailand; Pluangklang.c248@gmail.com

* Correspondence: kunwadee@sut.ac.th

Abstract: In this work, simple conditions were applied to modify bentonite for the removal of pesticides from aqueous solution. Bentonite was modified in a single step as $\mathrm{BA}_{0.5}$ (with $\mathrm{HCl}$ $0.5 \mathrm{M}$ ) and $\mathrm{BC}_{500}$ (calcined at $500{ }^{\circ} \mathrm{C}$ ) and combined steps with different sequences $\left(\mathrm{BA}_{0.5} \mathrm{C}_{500}\right.$ and $\mathrm{BC}_{500} \mathrm{~A}_{0.5}$ ). These adsorbents were characterised by XRD, XRF, FT-IR, ${ }^{27} \mathrm{Al}$ MAS NMR, BET, $\mathrm{NH}_{3}$-TPD, TGA, HPLC, particle size analysis and zeta potential. Single-component adsorption with atrazine, diuron, 2,4-D and paraquat was used in aqueous solution at various pesticide concentrations, contact times and $\mathrm{pH}$ levels. It was found that the sequence of the treatment significantly affected atrazine adsorption. $\mathrm{BC}_{500} \mathrm{~A}_{0.5}$ exhibited the highest efficiency for atrazine adsorption in a broad $\mathrm{pH}$ range of 3.0-9.0. Its adsorption at $\mathrm{pH} 6.0$ was about 12 times greater than that of other adsorbents with an initial atrazine concentration of $50 \mathrm{mg} \mathrm{L}^{-1}$, which indicates $\mathrm{BC}_{500} \mathrm{~A}_{0.5}$ specifically for the adsorption of atrazine. In addition, for the simultaneous adsorption of all four pesticides, $\mathrm{BC}_{500} \mathrm{~A}_{0.5}$ was found to remove the maximum total amount of the pesticides, indicating that it could be used as a good multifunctional adsorbent. All modified bentonites showed similar diuron adsorption better than that of unmodified bentonite. The greatest adsorption of 2,4-D prefers $\mathrm{BA}_{0.5} \mathrm{C}_{500}$, occurring at $\mathrm{pH}$ 2-4. In the case of paraquat adsorption, all adsorbents are good at absorbing paraquat, but bentonite had the highest rate of paraquat removal, whereas $\mathrm{BA}_{0.5} \mathrm{C}_{500}$ was found to have the lowest, and the adsorption increased with increasing $\mathrm{pH}$. Furthermore, the adsorption process on the adsorbents fits well with the Langmuir isotherm and pseudo-second-order kinetics models, as the thermodynamic parameters showed a spontaneous and endothermic process.

Keywords: bentonite; pesticides; acid-activation; heat-treatment; modified clay

\section{Introduction}

Toxic pesticides have a significant impact on human health as well as aquatic life. Currently, it is a topic of significant concern because of the increasing use of pesticides in agriculture and domestic activities [1-7]. Therefore, it is necessary to find ways to limit the agrochemical substances discharged into the environment as much as possible, while also acting to eventually eliminate them completely.

Adsorption is a simple and convenient method for the removal of compounds compared to other physical, chemical, or biological technologies. It also involves low investment in terms of both initial cost and land required. Various solid substrates offer good adsorptive properties, including zeolites, activated carbon, fly ash, mesoporous silica and clay minerals, which were applied in the removal of organic contaminants from water [2,8-14].

Bentonite clay minerals are available not only in Thailand, but their deposits are widespread all over the word. They are an important, low-cost source of montmorillonite and exhibit excellent adsorption capacities as well as high cation exchange capability (CEC) $[15,16]$. The major component of bentonite is montmorillonite, a dioctahedral smectite. Montmorillonite is a porous clay mineral consisting of a 2:1-layered structure, with alternating layers of exchangeable cations. The layers consist of octahedral alumina sheets 
that are sandwiched by two tetrahedral silica sheets. Substituting $\mathrm{Al}^{3+}$ for $\mathrm{Si}^{4+}$ in the silica tetrahedral sheets and $\mathrm{Mg}^{2+}$ for $\mathrm{Al}^{3+}$ in the alumina octahedral sheets produced a net negative charge, which is usually balanced by adsorbed cations. These cations are easily replaced by either organic or inorganic cations, accounting for the unique hydrophilic, tumescent, and adsorption properties of montmorillonite $[17,18]$. As in previous reports, the type and concentration of the acid effect on modified clay were used for the removal of organic substance [19-22]. $\mathrm{HCl}$ acid is usually modified for this purpose according to its multifunctional groups such as silanol, so that it can be as efficient adsorbent. Furthermore, mild conditions can stabilise clay structure and the effect of heat used in the modification process was also promoted for the removal of organic compounds [23,24] Acid and heat modification optimises the physical characteristics of bentonite for the removal of contaminants by causing structural and textural changes within the clay, thus enhancing the adsorption capacity. Acid and thermal treatments are low cost methods that require few chemicals and are simple to apply. Acid-activated bentonite is suitable for the removal or elimination of impurities; it increases both porous surface area and the numbers of silanol groups present in the clay, which are important for the adsorption of organic compounds $[25,26]$. Heat treatment significantly alters the surface properties of bentonite; it improves porosity by increasing mesopore volume, increases the number of surface adsorption sites, and increases the number of siloxane groups present while reducing the number of hydroxyl groups present $[23,27-30]$. In addition to these structural changes, both acid and heat treatments alter the textural properties of the clay and improve its dispersibility in water. As mentioned above, the use of heat and acid for treatments can promote pesticide adsorption performance. Thus, we are interested in using these treatments to modify bentonite by combining both treatments rather than solely with heat or acid, and we additionally consider the sequence of each treatment in the modification of bentonite in order to optimise active sites for the adsorption of different types of pesticides such as atrazine (basic), diuron (non-ionic), 2,4-D (acidic) and paraquat (cation) in aqueous media, including the investigation of the simultaneous adsorption of these pesticides to evaluate the potential of these adsorbents for application as multifunctional adsorbents. Isotherms, kinetic modelling and thermodynamic parameters of the adsorptions were investigated as well.

\section{Material and Methods}

\subsection{Materials}

Bentonite (B) was purchased from Thai Nippon Chemical Industry Co., Ltd. (Samut Sakhon, Thailand) Tables 1 and 4 list the chemical and physical properties of bentonite. Reagent grade atrazine (6-chloro-N2-ethyl-N4-(propan-2-yl)-1,3,5-triazine-2,4-diamine) (99.5\% purity), diuron (3-(3,4-Dichlorophenyl)-1,1-dimethylurea) (99.6\% purity), 2,4-D (2,4dichlorophenoxy acetic acid) (99.9\% purity) and paraquat (1,1'-Dimethyl-4, $4^{\prime}$-bipyridinium dichloride) (98\% purity) were obtained from Sigma-Aldrich.

\subsection{Preparation of Modified Bentonite}

Bentonite was sieved with a $63 \mu \mathrm{m}$ mesh and dried overnight at $110^{\circ} \mathrm{C}$ before being used in the modification. Single-step modified bentonite (modified by either acid or heat) and two-step-modified samples (modification with both acid and heat) were prepared using the following procedures:

Acid treatment: Bentonite (4 g) was activated by immersion in $100 \mathrm{~mL} \mathrm{HCl}(37 \%)$ (AR grad, Sigma-Aldrich) at various concentrations $(x=0.1-3 \mathrm{M} \mathrm{HCl})$ at $100^{\circ} \mathrm{C}$ for $6 \mathrm{~h}\left(\mathrm{BA}_{\mathrm{x}}\right)$. Then, the mixture was centrifuged and washed with deionised-water (DI water) to ensure the removal of chloride ions, then dried in an oven overnight at $110^{\circ} \mathrm{C}$. The $\mathrm{B} \mathrm{A}_{X}$ samples were stored in a desiccator.

Heat treatment: Bentonite $(4 \mathrm{~g})$ was calcined at various temperatures $\left(\mathrm{y}=300-600^{\circ} \mathrm{C}\right)$ for $12 \mathrm{~h}$. $\left(\mathrm{BC}_{\mathrm{y}}\right)$ was then cooled in a desiccator. 
Combined acid and heat treatments: The obtained $\mathrm{BA}_{\mathrm{x}}$ and $\mathrm{BC}_{\mathrm{y}}$ samples were tested for atrazine, diuron, 2,4-D, and paraquat adsorption. The sample activated with $0.5 \mathrm{M} \mathrm{HCl}$ $\left(\mathrm{BA}_{0.5}\right)$ and the $500{ }^{\circ} \mathrm{C}$ heat-treated sample $\left(\mathrm{BC}_{500}\right)$ exhibited the best pesticide adsorption (data not shown). Therefore, the $\mathrm{BA}_{0.5}$ and $\mathrm{BC}_{500}$ were selected for combined acid and heat treatment. The $\mathrm{BA}_{0.5} \mathrm{C}_{500}$ sample was prepared by the calcination of $\mathrm{BA}_{0.5}(4 \mathrm{~g})$ at $500{ }^{\circ} \mathrm{C}$ for $12 \mathrm{~h}$. $\mathrm{BC}_{500} \mathrm{~A}_{0.5}$ was prepared following the same procedure, however, using $\mathrm{BC}_{500}$ in place of bentonite.

\subsection{Characterisation}

The chemical compositions of the major elements in bentonite and modified bentonite were determined by energy dispersive XRF (EDS, Oxford Instrument ED 2000, Abingdon, UK) using an Rh X-ray tube with a vacuum medium. The CEC was determined by a 9080 CEC standard method (US EPA, OSWER), in which all adsorbed cations in a bentonite sample were replaced by a common ion, such as $\mathrm{NH}_{4}{ }^{+}$, and then the amount of adsorbed common ion was determined. The interlayer spacing of the samples was determined by $\mathrm{X}$ Ray diffraction patterns obtained from back-pressed powder samples recorded on a Bruker, D5005, Germany, $\mathrm{Cu} \mathrm{K} \alpha$ radiation, scanning from $3^{\circ}$ to $50^{\circ}$ at a rate of $0.05^{\circ} / \mathrm{s}$ at $35 \mathrm{mV}$ and $35 \mathrm{~mA}$. The framework and $\mathrm{OH}$ groups were confirmed by FT-IR spectroscopy (Spectrum GX, Perkin-Elmer, Waltham, MA, USA) as KBr pellets, over the range of $4000-400 \mathrm{~cm}^{-1}$ and near-IR diffuse reflection (DRIFT) in the range of $8000-4000 \mathrm{~cm}^{-1}$. The DRIFT technique was especially appropriate in this region because no sample dilution was required. Specific surface and pore size distributions were evaluated by nitrogen gas adsorption at $-196{ }^{\circ} \mathrm{C}$ using a BEL JAPAN, BELSORP-mini II, Japan instrument, with the Brunauer-EmmerttTeller (BET) method. All samples were characterised by solid-state ${ }^{27} \mathrm{Al} \mathrm{CP} / \mathrm{MAS}$ NMR (JEOL JNM-ECA600), with a static $11 \mathrm{~T}$ magnetic field at a spin rate of $11 \mathrm{kHz}$. The ${ }^{27} \mathrm{Al}$ $\mathrm{CP} / \mathrm{MAS}$ NMR spectra were recorded at a frequency of $130 \mathrm{MHz}$. The NMR reference used was $\mathrm{Al}\left(\mathrm{NO}_{3}\right)_{3} .9 \mathrm{H}_{2} \mathrm{O}$ with a chemical shift of $0.00 \mathrm{ppm}$. The particle size distributions (PDS) of all samples were analysed by a Horiba laser-scattering particle-size-distribution analyser (LA-950), Japan. The active site was determined using $\mathrm{NH}_{3}$ temperature-program desorption (TPD) apparatus (BEL Japan, model BELCAT-B, Osaka, Japan). Samples were pre-treated at $300{ }^{\circ} \mathrm{C}$ for $2 \mathrm{~h}$ and then exposed to a flow of $\mathrm{NH}_{3} / \mathrm{He}$ at $100{ }^{\circ} \mathrm{C}$ for $30 \mathrm{~min}$. Weakly adsorbed $\mathrm{NH}_{3}$ was removed by flushing with $\mathrm{He}$ gas at $100{ }^{\circ} \mathrm{C}$ for $30 \mathrm{~min}$. $\mathrm{The}_{3}$ TPD profile was obtained over the range of $100^{\circ} \mathrm{C}-600^{\circ} \mathrm{C}$ at a heating rate of $10{ }^{\circ} \mathrm{C} / \mathrm{min}$. Desorbed $\mathrm{NH}_{3}$ was detected using a thermal conductivity detector. TGA curves were obtained by heating the sample in an alumina70 cell from 30 to $800{ }^{\circ} \mathrm{C}$ at a heating rate of $10^{\circ} \mathrm{C} \mathrm{min}^{-1}$ under air atmosphere using a thermogravimetric analyser (TGA-DSC, METTLER, Germany). Zeta potential measurements were performed using a Malvern, UK. Bentonite and modified bentonite slurries were homogenised using a Branson Sonifier, UK. Sonifier employs ultrasonic vibration to disperse the dry clay particle aggregates in suspensions. Before the sonication, the amount of clay powder and deionised (DI) water was kept constant at $10 \mathrm{wt}$ \%. Dilution suspensions were prepared for the zeta potential measurement with a colloidal Dynamics Zeta Probe. The concentration employed was only $1 \mathrm{wt}$ \% solids. The $\mathrm{pH}$ was increased to approximately 12 with $1 \mathrm{M} \mathrm{NaOH}$ before commencing the yield stress measurements. Concentrated $\mathrm{HCl}(1 \mathrm{M})$ was added dropwise to decrease the $\mathrm{pH}$ in a stepwise manner.

Atrazine, diuron, 2,4-D, and paraquat concentration were determined using UVvisible spectrophotometry at 223, 247, 283 and $257 \mathrm{~nm}$, respectively (T80 + UV-Vis spectrophotometer PG instruments, Alma Park, Leicestershire, UK). The mixture solution of atrazine, diuron, 2,4-D and paraquat concentration were determined using HPLC (Hewlett Packard series 1100, Palo Alto, CA, USA). All experimental measurements were made in duplicate. The quantity of adsorbed atrazine, diuron, 2,4-D and paraquat by bentonite 
and modified bentonite was calculated from the difference between the initial and final pesticide concentrations using the mass balance Equation (1):

$$
\mathrm{q}_{\mathrm{e}}=\frac{\mathrm{V}\left(\mathrm{C}_{\mathrm{i}}-\mathrm{C}_{\mathrm{e}}\right)}{\mathrm{M}}
$$

where $\mathrm{q}_{\mathrm{e}}$ is the adsorbed pesticide remaining on adsorbents $\left(\mathrm{mg} \mathrm{g}^{-1}\right)$ and $\mathrm{C}_{\mathrm{i}}$ and $\mathrm{C}_{\mathrm{e}}$ are the initial and final pesticide concentrations $\left(\mathrm{mg} \mathrm{L}^{-1}\right)$, respectively. $\mathrm{M}$ is the mass of adsorbent $(\mathrm{g})$, and $\mathrm{V}$ is the volume of the pesticide solution $(\mathrm{L})$.

\subsection{Batch Adsorption}

All adsorbents were dried overnight at $110{ }^{\circ} \mathrm{C}$ prior to commencing the adsorption study. Adsorption experiments were performed using a batch adsorption procedure with $20 \mathrm{mg}$ of bentonite or modified bentonite added to $10 \mathrm{~mL}$ of pesticide solution, which was then kept in a shaker bath at $30{ }^{\circ} \mathrm{C}$ for $24 \mathrm{~h}$ (equilibrium time $\sim 12 \mathrm{~h}$ ). The stock solution was prepared in methanol solutions; final methanol concentrations were less than $0.5 \%$ $(v / v)$ to prevent co-solvent effects. Suspensions were centrifuged at $3500 \mathrm{rpm}$ and then filtered. Each pesticide concentration in filtrates was determined by UV-Vis spectroscopy.

\subsection{Effect of $p H$}

The effect of $\mathrm{pH}$ on the adsorption of atrazine, diuron, 2,4-D, and paraquat by bentonite and modified bentonite was investigated over the $\mathrm{pH}$ range of 2.0-12.0. Pesticide solutions were prepared by dissolving the samples in distilled water. The adsorbents were exposed to the pesticide solution at a solid/liquid ratio of $20 \mathrm{mg} / 10 \mathrm{~mL}$. The solution $\mathrm{pH}$ was adjusted by adding 0.1 or $0.01 \mathrm{M}$ of $\mathrm{HCl}$ or $\mathrm{NaOH}$ solution, as appropriate. The mixture was placed in a shaker at $30^{\circ} \mathrm{C}$ until it reached equilibrium, then centrifuged to separate the filtrate from the solid phase. The filtrate was analysed for residual pesticide concentration. Duplicate tests were performed in all cases.

\subsection{Simultaneous Adsorption of Various Pesticides in Solutions}

The aqueous adsorbate solutions used in the adsorption study were: (i) a singlecomponent (each pesticide); and (ii) a quaternary-component solution of atrazine, diuron, 2,4-D and paraquat. The initial concentration of each pesticide was $50 \mathrm{mg} \mathrm{L}^{-1}$. The initial $\mathrm{pH}$ value was unadjusted $(6.5 \pm 0.5)$. The experiments were realised at room temperature using equal volumes of the pesticide solutions, $\mathrm{V}=10.0 \mathrm{~mL}$. The mass of adsorbent in all adsorption studies was $20.0 \mathrm{mg}$. In the quaternary-component solution of the pesticides, the adsorption capacity of individual pesticides on bentonite and modified bentonite was investigated. The quaternary-component solution with $10 \mathrm{~mL}$ of each pesticide concentration $50 \mathrm{mg} \mathrm{L}^{-1}$ was added into $20 \mathrm{mg}$ of adsorbent. The adsorption experiments were performed in a shaker and then kept in a shaker for $24 \mathrm{~h}$. Suspensions were centrifuged at $3500 \mathrm{rpm}$ and then filtered. Each pesticide concentration in filtrates was determined by UV-Vis spectroscopy. The quaternary-component solution containing all the investigated pesticides (atrazine, diuron, 2,4-D and paraquat) was determined by HPLC (Hewlett Packard series 1100) with a diode array detector and UV detector. The ZORBAX Eclipse ODS C18 column (250 $\mathrm{mm} \times 4.6 \mathrm{~mm}$, particle size $5 \mu \mathrm{m}$ ) was equipped with the HPLC system and the UV detector wavelength was set at 201, 223, 254 and $283 \mathrm{~nm}$. Acetonitrile (A) and water pesticide ( $2 \%$ phosphoric acid) (B) were used as mobile phases. The gradient program of HPLC was as follows: $0-13 \mathrm{~min} 100 \% \mathrm{~B} ; 3-15 \mathrm{~min} 60 \% \mathrm{~A}$ and $40 \% \mathrm{~B} ; 15-18 \mathrm{~min} 100 \%$ (A) and $20-30 \mathrm{~min} 100 \% \mathrm{~A}$. The flow rate was set at $0.9 \mathrm{~mL} \mathrm{~min}^{-1}$.

\subsection{Adsorption Isotherm}

Adsorption isotherms for atrazine, diuron, 2,4-D and paraquat were acquired by batch equilibration using $20 \mathrm{mg}$ of bentonite or modified bentonite in $10 \mathrm{~mL}$ of aqueous pesticide solution at various concentrations $\left(10-120 \mathrm{mg} \mathrm{L}^{-1}\right)$ at $6.0 \pm 0.5$. The $\mathrm{pH}$ values were checked before and after adsorption measurement to ensure a small change of $\mathrm{pH}$ 
values. After equilibration ( $12 \mathrm{~h}$ ), solid and liquid phases were separated by centrifugation. Atrazine, diuron, 2,4-D, and paraquat concentration were determined spectrophotometrically by measuring absorbance at $223,247,283$, and $257 \mathrm{~nm}$, respectively. Data obtained from the adsorption tests were used to calculate the adsorption capacity, $\mathrm{q}_{\mathrm{e}}\left(\mathrm{mg} \mathrm{g}^{-1}\right)$. The adsorption isotherms were evaluated by applying the Langmuir and Freundlich models.

\subsection{Kinetic and Thermodynamics Adsorption Study}

Kinetic adsorption experiments were performed at $30^{\circ} \mathrm{C}$ by contacting the adsorbents with pesticide solutions at a solid/liquid ratio of $20 \mathrm{mg} / 10 \mathrm{~mL}$. In the first phase of the study, the mixtures were shaken and the supernatants were collected at the following times: $2,4,6,8,10,30,60,90,120,180,240,360,720,1080$ and $1440 \mathrm{~min}$. Afterward, supernatants were centrifuged and measured spectrophotometrically at 223, 247, 283 and $257 \mathrm{~nm}$. All of the batch tests were performed in duplicate. Average values were used in the calculation. Deviations were less than $2 \%$. In order to determine the adsorption properties at different temperatures, the above experiments were repeated at 303,313 and $323 \mathrm{~K}$. To evaluate the adsorption thermodynamics of pesticides onto the adsorbent, enthalpy $(\Delta \mathrm{H})$, entropy $(\Delta \mathrm{S})$ and free energy $(\Delta G)$ changes explained the thermodynamic data for adsorption process, which were calculated by Equations (4) and (5).

\section{Results and Discussion}

\subsection{Characterisation of Bentonite and Modified Bentonite}

\subsubsection{XRF and CEC Analysis}

Table 1 shows the effects of acid and heat treatment on the chemical and CEC properties of the adsorbents. Acid treatment has a significant effect on chemical composition. The weight percentage of oxide metal of $\mathrm{Na}^{+}, \mathrm{Mg}^{2+}, \mathrm{K}^{+}, \mathrm{Ca}^{2+}, \mathrm{Fe}^{3+}$, and of $\mathrm{Al}^{3+}$ decreases significantly during treatment with acid in both single- and two-step modified samples, such as $\mathrm{BA}_{0.5}, \mathrm{BC}_{500} \mathrm{~A}_{0.5}$, and $\mathrm{BA}_{0.5} \mathrm{C}_{500}$ resulting from the effects of acid leaching. When comparing the $\mathrm{SiO}_{2} / \mathrm{Al}_{2} \mathrm{O}_{3}$ ratios of $\mathrm{BC}_{500} \mathrm{~A}_{0.5}$ and $\mathrm{BA}_{0.5} \mathrm{C}_{500}$, it shows that $\mathrm{BA}_{0.5} \mathrm{C}_{500}$, treated with acid prior to heat treatment has a higher $\mathrm{SiO}_{2} / \mathrm{Al}_{2} \mathrm{O}_{3}$ ratio (see Table 1), probably due to the calcined sample $\left(\mathrm{BC}_{500}\right)$ with larger mean particle sizes than unmodified bentonite before further treatment with acid (as mentioned in Topic 3.1.8). There are various methods available to determine CEC. Most approaches involve the complete exchange of naturally occurring cations in a clay mineral with a cationic species such as ammonium ion, followed by the removal of excess substitution ion and the determination of the amount retained in the clay interlayer [15]. It was found that CEC values for acid and heat-treated samples are lower than those for bentonite (see Table 1).

Table 1. Chemical composition and CEC values for bentonite and modified bentonite samples.

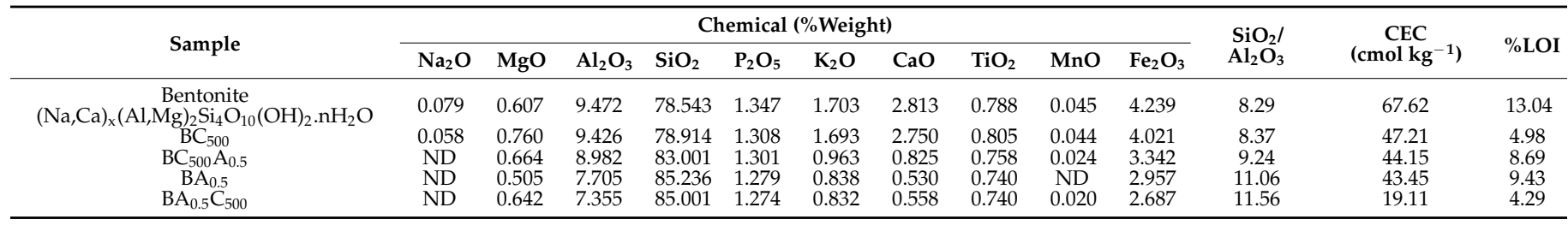

The decrease in CEC value with acid treatment results from cationic leaching, while low CEC values resulting from heat treatment may be explained by a charge reduction as the result of the migration of small radii cations into vacant octahedral sites and the formation of covalent bonds after heating [31]. Another explanation is that the cation becomes more strongly bound to the surface during calcination, so the exchange by $\mathrm{NH}_{4}{ }^{+}$ becomes more difficult. However, the extent of charge reduction depends on the nature of the cation and the heating temperature. 


\subsubsection{XRD Analysis}

The swelling of bentonite is a consequence of its hydrated structure, in which cations are located in the interlayer space and solvated by water molecules adsorbed from the atmosphere [31]. XRD patterns of bentonite (34.8\% montmorillonite) (Figure 1) show characteristic diffraction peaks at $20=6.3,19.8$ and 34.9. Quartz $(\mathrm{Q})$ and cristobalite $(\mathrm{C})$ impurities are observed in the patterns. The $\mathrm{d}_{001}$ reflection at $2 \theta=6.30$ corresponds to d-spacing $=14.02 \AA$, which is an interlayer comprising the mono- and bi-layers of water molecules [32,33]. A decrease in d-spacing from calcination was caused by the removal of interlayer water and the migration of exchangeable cation [31]. Moreover, $\mathrm{d}$-spacing decreases from the acid treatment result from the removal of some cations. $\mathrm{BC}_{500}$ shows d-spacing $=9.65 \AA$, while $\mathrm{BA}_{0.5}$ shows $\mathrm{d}_{001}=13.00 \AA$, as shown in Table 2, indicating that heat treatment significantly affects basal spacing. All adsorbents, except $\mathrm{BC}_{500}$, show small changes in d-spacing after the pesticide adsorptions, excluding paraquat, suggesting that the pesticides probably bind to the active sites of the face and edge, whereas the pesticides adsorptions may also involve the interlayer space for $\mathrm{BC}_{500}$. In the case of $\mathrm{d}$-spacing for cationic pesticide (paraquat), it shows a similar value (12.05-12.38 $\AA$ ), except $\mathrm{BA}_{0.5} \mathrm{C}_{500}$, suggesting that hydrated paraquat possibly exchanges in the interlayer space with a smaller size compared to interlayer water.

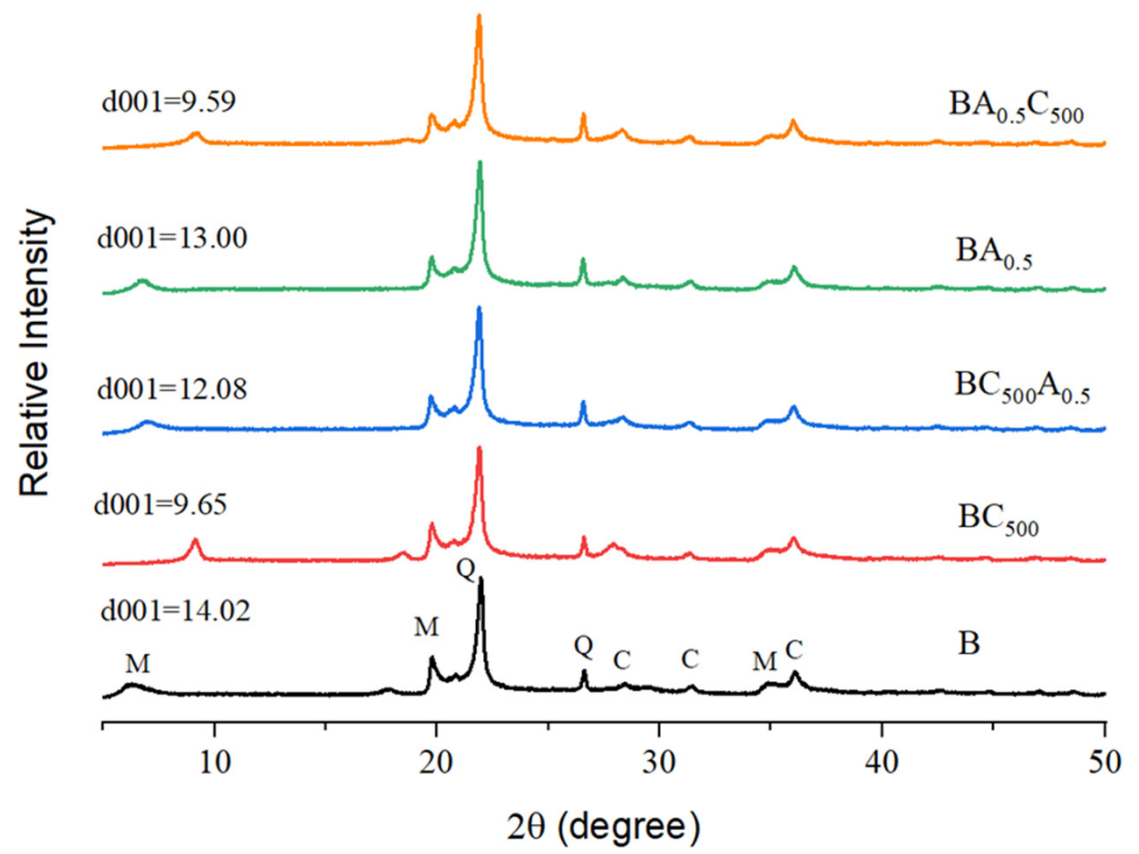

Figure 1. $\mathrm{XRD}$ patterns for bentonite (B), $\mathrm{BC}_{500}, \mathrm{BC}_{500} \mathrm{~A}_{0.5}, \mathrm{BA}_{0.5}$, and $\mathrm{BA}_{0.5} \mathrm{C}_{500}$ adsorbents. ( $\mathrm{Q}=$ quartz; $\mathrm{M}=$ montmorillonite; $\mathrm{C}=$ cristobalite.).

Table 2. The d-spacing ( $(\AA)$ of bentonite and modified bentonite changes upon atrazine, diuron, 2,4-D, and paraquat adsorption.

\begin{tabular}{cccccc}
\hline \multirow{2}{*}{ Samples } & \multicolumn{5}{c}{ d-spacing $(\AA)$} \\
\cline { 2 - 6 } & No Adsorption & Atrazine & Diuron & 2,4-D & Paraquat \\
\hline Bentonite & 14.02 & 14.59 & 14.01 & 14.21 & 12.27 \\
$\mathrm{BC}_{500}$ & 9.65 & 12.38 & 12.29 & 12.90 & 12.05 \\
$\mathrm{BA}_{0.5}$ & 13.00 & 13.71 & 12.47 & 13.36 & 12.16 \\
$\mathrm{BC}_{500} \mathrm{~A}_{0.5}$ & 12.08 & 12.76 & 12.17 & 12.54 & 12.38 \\
$\mathrm{BA}_{0.5} \mathrm{C}_{500}$ & 9.59 & 9.51 & 9.32 & 9.21 & 9.70 \\
\hline
\end{tabular}




\subsubsection{Thermogravimetric Analysis}

The weight loss observed between $50{ }^{\circ} \mathrm{C}$ and $150{ }^{\circ} \mathrm{C}$ and between $150{ }^{\circ} \mathrm{C}$ and $400{ }^{\circ} \mathrm{C}$ is due to the evaporation of water adsorbed on the adsorbents and probably due to hydrated water bound tightly to cations, respectively. The amounts of water contained are shown in Table 3 and the supplementary information in Figure S1. This result shows that $\mathrm{BC}_{500}$ and $\mathrm{BA}_{0.5} \mathrm{C}_{500}$ possess low hydrophilic properties due to low water content. Above $500{ }^{\circ} \mathrm{C}$, the weight loss is traceable to the dehydration of some trapped water molecules in the interstices of the clay layers and due to dehydroxylation of the mineral, which is accompanied by a change in the crystal structure [34].

Table 3. Water content (\%) in bentonite and modified bentonite.

\begin{tabular}{ccc}
\hline Adsorbents & Weight Loss (\%) \\
\hline & $\mathbf{5 0 - 1 5 0}{ }^{\circ} \mathbf{C}$ & $\mathbf{1 5 0 - 4 0 0}{ }^{\circ} \mathbf{C}$ \\
\hline $\mathrm{B}$ & 7.83 & 2.50 \\
$\mathrm{BA}_{0.5}$ & 5.56 & 2.01 \\
$\mathrm{BC}_{500}$ & 1.03 & 1.41 \\
$\mathrm{BA}_{0.5} \mathrm{C}_{500}$ & 1.18 & 1.21 \\
$\mathrm{BC}_{500} \mathrm{~A}_{0.5}$ & 4.59 & 2.54 \\
\hline
\end{tabular}

\subsubsection{FT-IR Analysis}

The middle-IR and near-IR spectra of adsorbents are shown in Figures 2 and 3, respectively. A characteristic bentonite stretching band at $3626 \mathrm{~cm}^{-1}$ is attributed to $\mathrm{OH}-$ dioctahedral smectite. These spectra confirm that the modified bentonite samples are still characteristic of bentonite. Bands at $3420 \mathrm{~cm}^{-1}$ and $1636 \mathrm{~cm}^{-1}$ correspond to the stretching and bending vibrations of hydrogen-bonded water molecules [35]. After calcination, the spectra show a decrease in the intensities of the Al-Al-OH band at $913-920 \mathrm{~cm}^{-1}$ and the $\mathrm{Al}-\mathrm{Mg}-\mathrm{OH}$ band at $840 \mathrm{~cm}^{-1}$ for $\mathrm{BC}_{500}$ and $\mathrm{BA}_{0.5} \mathrm{C}_{500}$ samples, respectively, suggesting the occurrence of dehydroxylation during calcination and the partial leaching of octahedral Al cations in acid-treated samples $[19,28]$. Changes in the tetrahedral sheets are reflected in the position and shape of the $\mathrm{Si}-\mathrm{O}$ stretching band [35]. There is a slight decrease in the tetrahedral Si-O band intensity at $1039 \mathrm{~cm}^{-1}$ for modified samples. We assigned this to $\mathrm{Si}-\mathrm{O}$ vibrations within a three-dimensional amorphous phase formed during the acid and thermal treatments [35]. Two bands at 520 and $469 \mathrm{~cm}^{-1}$ correspond to bending vibrations of Al-O-Si and $\mathrm{Si}-\mathrm{O}-\mathrm{Si}$, respectively. The band at $520 \mathrm{~cm}^{-1}$ is the most sensitive band in the presence of any remaining $\mathrm{Al}^{3+}$ species in the octahedral sheets and two samples of $\mathrm{BA}_{0.5}$ and $\mathrm{BA}_{0.5} \mathrm{C}_{500}$ obviously show those with a broader band. The band at $622 \mathrm{~cm}^{-1}$ results from coupled $\mathrm{Al}-\mathrm{O}$ and $\mathrm{Si}-\mathrm{O}$ out-of-plane vibrations [36].

NIR spectra were recorded to determine the $\mathrm{Si}-\mathrm{OH}$ groups in the adsorbent (Figure 3). The bands at $4533 \mathrm{~cm}^{-1}$ and $7078 \mathrm{~cm}^{-1}$ are assigned to the combination mode and first overtones $\left(2 v_{\mathrm{OH}}\right)$ of structural $\mathrm{OH}$ groups, respectively, while the band at $5240 \mathrm{~cm}^{-1}$ corresponds to the combination mode of water molecules $[26,28] . \mathrm{BA}_{0.5}, \mathrm{BA}_{0.5} \mathrm{C}_{500}$, and $\mathrm{BC}_{500} \mathrm{~A}_{0.5}$ shows a new band at $7319 \mathrm{~cm}^{-1}$ assigned to the first overtone for silanol $\left(2 v_{\mathrm{Si}-\mathrm{OH}}\right)$, confirming the formation of $\mathrm{Si}-\mathrm{OH}$ groups during treatment with acid [35]. 

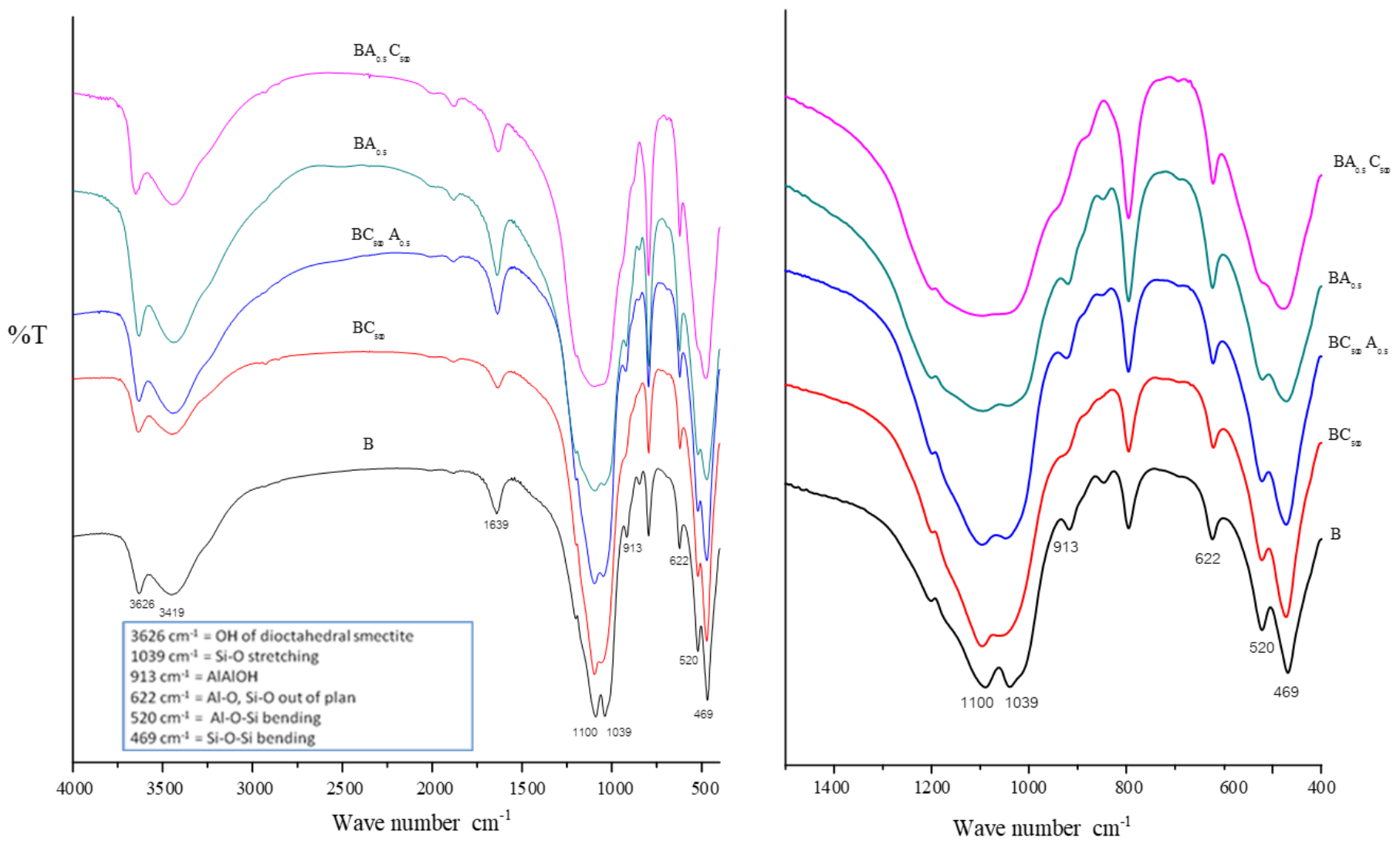

Figure 2. Mid FT-IR spectra of bentonite (B), $\mathrm{BC}_{500}, \mathrm{BC}_{500} \mathrm{~A}_{0.5}, \mathrm{BA}_{0.5}$ and $\mathrm{BA}_{0.5} \mathrm{C}_{500}$ samples.

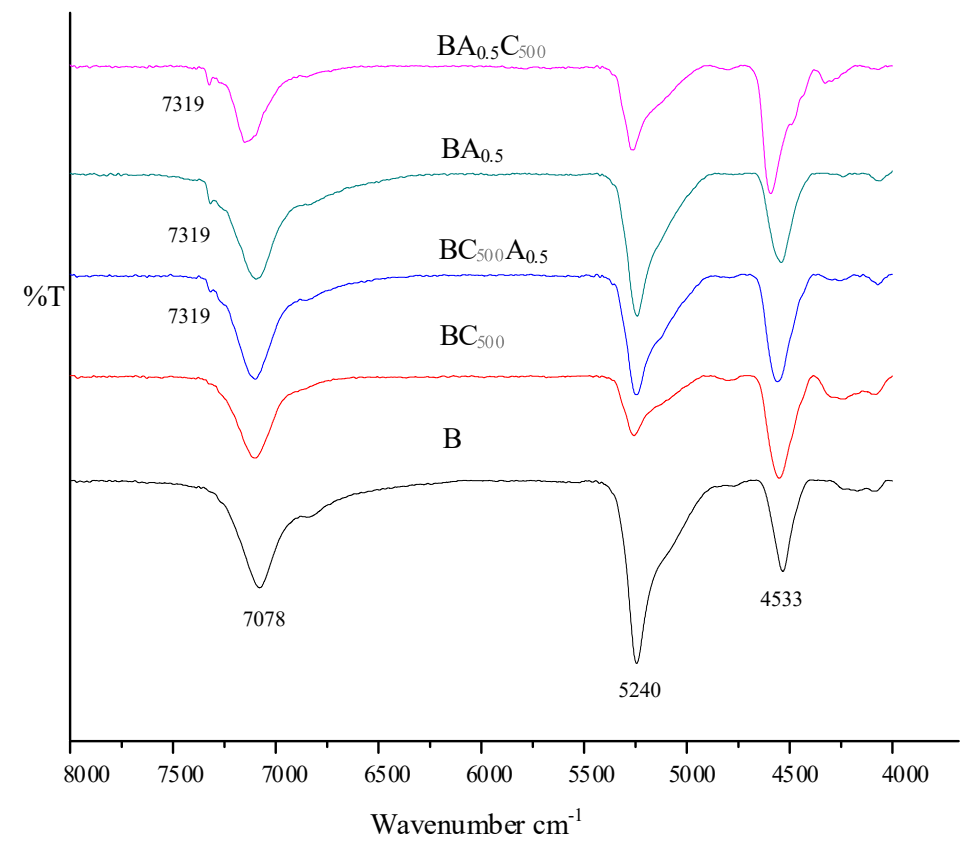

Figure 3. NIR FT-IR spectra of bentonite (B), $\mathrm{BC}_{500}, \mathrm{BC}_{500} \mathrm{~A}_{0.5}, \mathrm{BA}_{0.5}$ and $\mathrm{BA}_{0.5} \mathrm{C}_{500}$ samples.

\subsubsection{Temperature-Programmed Desorption of Ammonium ( $\left.\mathrm{NH}_{3}-\mathrm{TPD}\right)$}

The $\mathrm{NH}_{3}$-TPD profile provides information on the strength and density of adsorbent surface acid sites. The $\mathrm{NH}_{3}$-TPD profile of pristine bentonite shows three discrete desorption maximal peaks in the low-temperature region $\left(50-200^{\circ} \mathrm{C}\right)$, medium temperature region $\left(200-420^{\circ} \mathrm{C}\right)$, and high-temperature region $\left(420-800{ }^{\circ} \mathrm{C}\right)$, which are attributed to weak, 
medium, and strongly acidic sites, respectively [19]. Figure 4 shows $\mathrm{NH}_{3}$-TPD plots for bentonite and modified bentonite. All adsorbents exhibit a peak in the high-temperature region which corresponds to a strong acid site. We attribute this to the desorption of $\mathrm{NH}_{3}$ from $\mathrm{Al}$ on the surface of the adsorbent. The greatest density $\left(3.071 \mathrm{mmol} \mathrm{g}^{-1}\right)$ for these acid sites is seen for $\mathrm{BC}_{500} \mathrm{~A}_{0.5}$. The $\mathrm{NH}_{3}$-TPD profiles for acid-activated adsorbents show additional peaks in the mid-temperature region $\left(400-475^{\circ} \mathrm{C}\right)$ that can be ascribed to medium acidic $\mathrm{Si}-\mathrm{OH}_{2}{ }^{+}$sites [19].

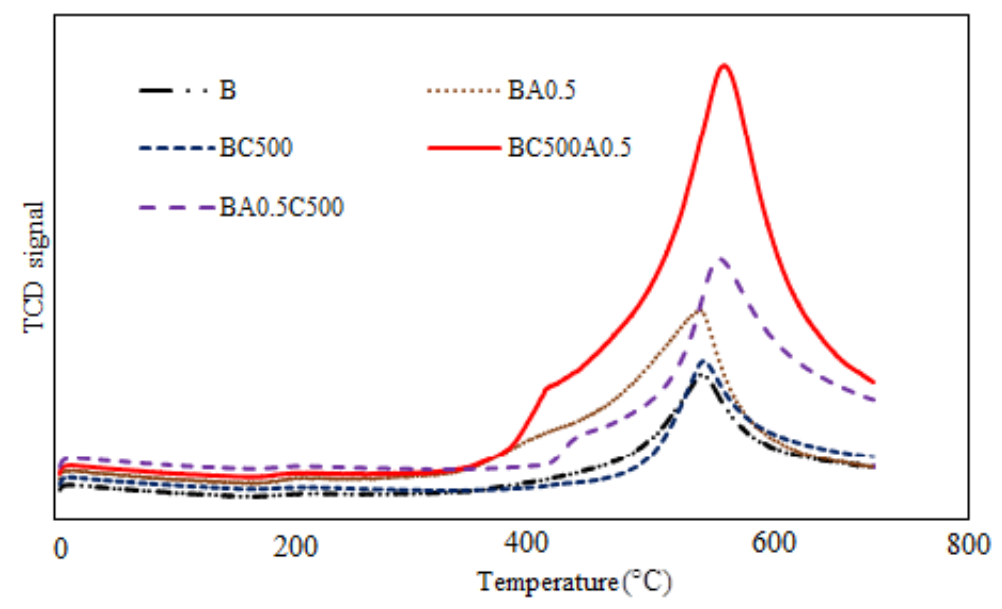

Figure 4. $\mathrm{NH}_{3}$-TPD profiles for bentonite and modified bentonite.

\subsubsection{NMR Analysis}

Figure 5 shows ${ }^{27} \mathrm{Al}$ MAS NMR spectra for all adsorbents. A major peak at $3.73 \mathrm{ppm}$ in the spectrum for bentonite arises from six-coordinate $\mathrm{Al}(\mathrm{Al}(\mathrm{VI}))$, indicating that much of the aluminium is located in octahedral environments. It is notable that the octahedral peak is split into the acid treatment performed in the final step. The two minor peaks at $68.25 \mathrm{Al}(\mathrm{IV}) \mathrm{a}$ and $55.76 \mathrm{Al}(\mathrm{IV}) \mathrm{b}$ are attributed to the four-coordinate tetrahedral $\mathrm{Al}^{3}(3 \mathrm{Si})$ and $\mathrm{Q}^{4}(4 \mathrm{Si})$ core units, respectively $[37,38]$. This minor peak area decreases after modification with acid. The result suggests that four-coordinate tetrahedral $\mathrm{Al}$ is easily removed. In the case of calcination $\left(\mathrm{BC}_{500}\right)$, the observed decrease in $\mathrm{Al}(\mathrm{IV})$ peak may result from some $\mathrm{Al}$ in the bentonite tetrahedral sheets probably being substituted by other cations such as $\mathrm{Mg}^{2+}$ and $\mathrm{Ca}^{2+}$ due to cation migration, which corresponds to previous reports [28,39]. In summary, these arguments account for the disappearance of two minor peaks of tetrahedral $\mathrm{Al}$. A small increase in $\mathrm{Al}(\mathrm{IV})$ peak high for $\mathrm{BC}_{500} \mathrm{~A}_{0.5}$ may result from $\mathrm{Al}$ adopting a tetrahedral site. The $\mathrm{NH}_{3}$-TPD results indicate that the adsorbents contain $\mathrm{Al}$ Lewis-acid sites (three-coordinate $\mathrm{Al}$ ), consistent with literature reports [37], although this is not apparent from ${ }^{27} \mathrm{Al} \mathrm{NMR} \mathrm{spectra.}$

\subsubsection{Textural Properties Study}

Table 4 shows the specific surface area, pore surface area, pore volume, and zeta potential for all adsorbents. The $\mathrm{BC}_{500}$ sample shows little change in these properties. However, the samples treated with acid, either in a single step or in combination with heat treatment $\left(\mathrm{BA}_{0.5}, \mathrm{BA}_{0.5} \mathrm{C}_{500}\right.$ and $\left.\mathrm{BC}_{500} \mathrm{~A}_{0.5}\right)$, see increases in specific surface area and pore volume; these increases may result from larger cations such as $\mathrm{Na}^{+}, \mathrm{Mg}^{2+}, \mathrm{K}^{+}, \mathrm{Ca}^{2+}$ and $\mathrm{Fe}^{3+}$, including $\mathrm{Al}^{3+}$ being replaced by very small $\mathrm{H}^{+}$cations based on the results of XRF (see Table 1) and FT-IR spectra (see Figure 2). Moreover, the zeta potential characterises the surface property of clay particles in suspension. The magnitude of this parameter is often used as a measure of the strength of the repulsive interactions between similarly charged particles. Table 4 shows the zeta potential of bentonite and modified bentonite suspension. In $\mathrm{pH} 7$, the zeta potential is negative for $\mathrm{B}, \mathrm{BC}_{500}, \mathrm{BC}_{500} \mathrm{~A}_{0.5}$, and $\mathrm{BA}_{0.5}$ and positive for $\mathrm{BA}_{0.5} \mathrm{C}_{500}$. Nonetheless, the permanent negative charge is very high in bentonite. This is due to the high degree of isomorphic substitution, where the $\mathrm{Al}(\mathrm{III})$ 
elements in the octahedral sheet are substituted by $\mathrm{Fe}(\mathrm{II})$ or $\mathrm{Mg}(\mathrm{II})$ in addition to some $\mathrm{Si}(\mathrm{IV})$ in the tetrahedral layer being substituted by $\mathrm{Al}(\mathrm{III})$ [40].
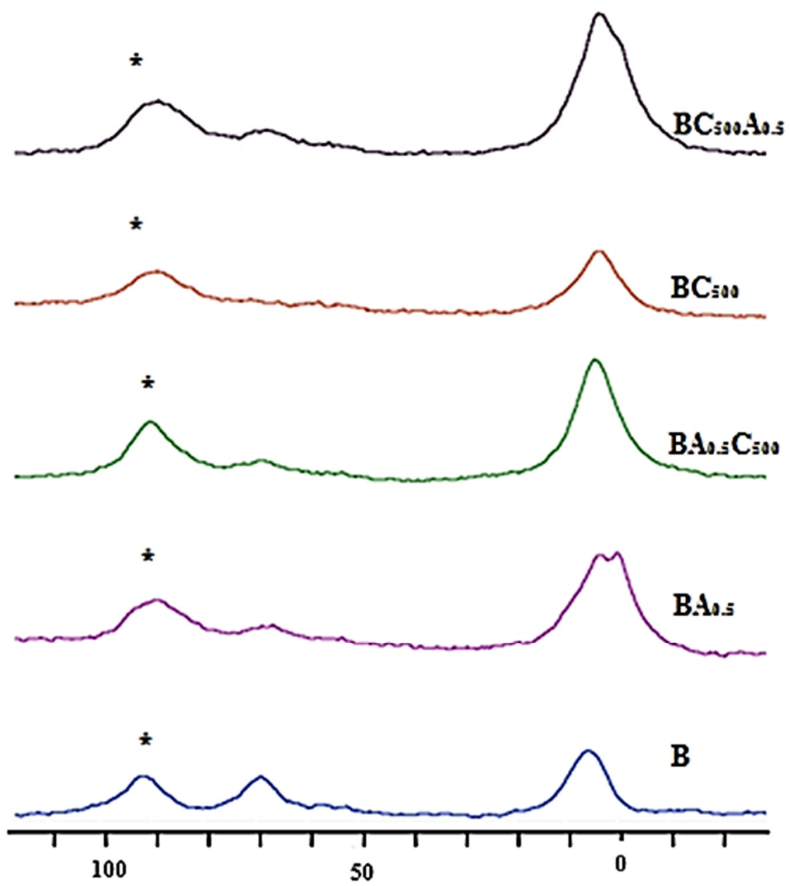

Chemical shift (ppm)

Figure 5. ${ }^{27} \mathrm{Al}$ MAS NMR spectra for bentonite and modified bentonite (Spinning side-bands are marked with asterisks).

Table 4. Surface area, mean pore diameter, and zeta potential of the bentonite and modified bentonite samples.

\begin{tabular}{cccccc}
\hline Main Characteristics & $\mathbf{B}$ & $\mathbf{B C}_{\mathbf{5 0 0}}$ & $\mathbf{B C}_{\mathbf{5 0 0}} \mathbf{A}_{\mathbf{0 . 5}}$ & $\mathbf{B A}_{\mathbf{0 . 5}}$ & $\mathbf{B A}_{\mathbf{0 . 5}} \mathbf{C}_{\mathbf{5 0 0}}$ \\
\hline Specific surface area $\left(\mathrm{m}^{2} / \mathrm{g}\right)$ & 31.76 & 32.19 & 67.86 & 77.12 & 80.09 \\
Pore surface area $\left(\mathrm{m}^{2} \mathrm{~g}^{-1}\right)$ & 30.901 & 31.301 & 55.354 & 64.704 & 69.154 \\
Pore volume $\left(\mathrm{cm}^{3} \mathrm{~g}^{-1}\right)$ & 0.1246 & 0.1247 & 0.1750 & 0.2281 & 0.2456 \\
Zeta potential $(\mathrm{mV})-\mathrm{pH} 7$ & -35.5 & -22.5 & -5.55 & -11.4 & 4.83 \\
\hline
\end{tabular}

\subsubsection{Particle Size Analysis}

The particle size distributions are shown in the supplementary information in Figure S2. The mean particle sizes of $\mathrm{B}, \mathrm{BC}_{500}, \mathrm{BC}_{500} \mathrm{~A}_{0.5}, \mathrm{BA}_{0.5}$ and $\mathrm{BA}_{0.5} \mathrm{C}_{500}$ are 7.15, 11.50, 8.71, 27.36 , and $97.08 \mu \mathrm{m}$, respectively (as mentioned in the supplementary information in Table S1). The samples were treated first with acid, $\mathrm{BA}_{0.5} \mathrm{C}_{500}$ and $\mathrm{BA}_{0.5}$ showing bimodal particle-size distribution. The $\mathrm{BA}_{0.5}$ sample has the maxima at approximately $11 \mu \mathrm{m}$ $(74.73 \%)$ and $25 \mu \mathrm{m}(25.27 \%)$ (Figure $\mathrm{S} 2 \mathrm{~b})$. The large particle size seen for $\mathrm{BA}_{0.5}$ may be due to the formation of a stable aggregate via hydrogen bonding between silanol groups, while $\mathrm{BA}_{0.5} \mathrm{C}_{500}$ exhibits the maxima at approximately $13 \mu \mathrm{m}(58.39 \%)$ and $229 \mu \mathrm{m}(41.61 \%)$ (Figure S2c). The larger particle size may result from the occurrence of dehydroxylation between the aggregated particles due to calcination. On the other hand, the particle size distributions for $\mathrm{BC}_{500} \mathrm{~A}_{0.5}$ and $\mathrm{BC}_{500}$ show only monomodal distributions, with maxima at about 9 and $11 \mu \mathrm{m}$, respectively (Figure S2d,e). The $\mathrm{BC}_{500} \mathrm{~A}_{0.5}$ particle size is smaller than that for $\mathrm{BC}_{500}$ due to acid erosion. 


\subsection{Adsorption of Pesticides onto Bentonite and Modified Bentonite}

\subsubsection{The Effect of $\mathrm{pH}$}

The changes in $\mathrm{pH}$ of the solution affect the speciation of adsorbate species, adsorbent surface charge, and degree of pesticide ionisation [41,42]. Bentonite can adsorb pesticides through two different mechanisms including cation exchange and adsorption [43]. Both mechanisms are $\mathrm{pH}$ dependent because most silanol and aluminol groups are protonated on the surface of bentonite under acid conditions. Thus, bentonite surface exists in a typically positive charge at low $\mathrm{pH}$ and the charge decreases, eventually becoming negative as $\mathrm{pH}$ increases.

Figure 6a shows the effect of $\mathrm{pH}$ on cationic pesticide (paraquat; $\mathrm{PQ}^{2+}$ ) adsorption by bentonite and modified bentonite. $\mathrm{PQ}^{2+}$ attaches to the active site through ion exchange, emerging mostly at the interlayer space of bentonite and the modified bentonite samples due to its small size, unlike the ion exchange of protonated atrazine (acidic form) that occurs very well at the face and edge of the adsorbents because of the large size of atrazine. The high adsorption of $\mathrm{PQ}^{2+}$ appears on bentonite and $\mathrm{BC}_{500}$ as shown in Figure 6a. The lowest adsorption of $\mathrm{PQ}^{2+}$ is on $\mathrm{BA}_{0.5} \mathrm{C}_{500}$. The high amount of adsorbed $\mathrm{PQ}^{2+}$ corresponds to the high value of CEC and negative zeta potential (see Tables 1 and 4). All adsorbents display the adsorption capacity of $\mathrm{PQ}^{2+}$, which increases with an increase in the $\mathrm{pH}$ of the solution, as shown in Figure 6a. The adsorption value of $\mathrm{PQ}^{2+}$ increases drastically at high $\mathrm{pH}$ because the surface of the adsorbents becomes more negatively charged, possibly due to the $\mathrm{SiOH}^{-}$group on the surface changing to $\mathrm{SiO}^{-}$that prefers to adsorb $\mathrm{PQ}^{2+}$.

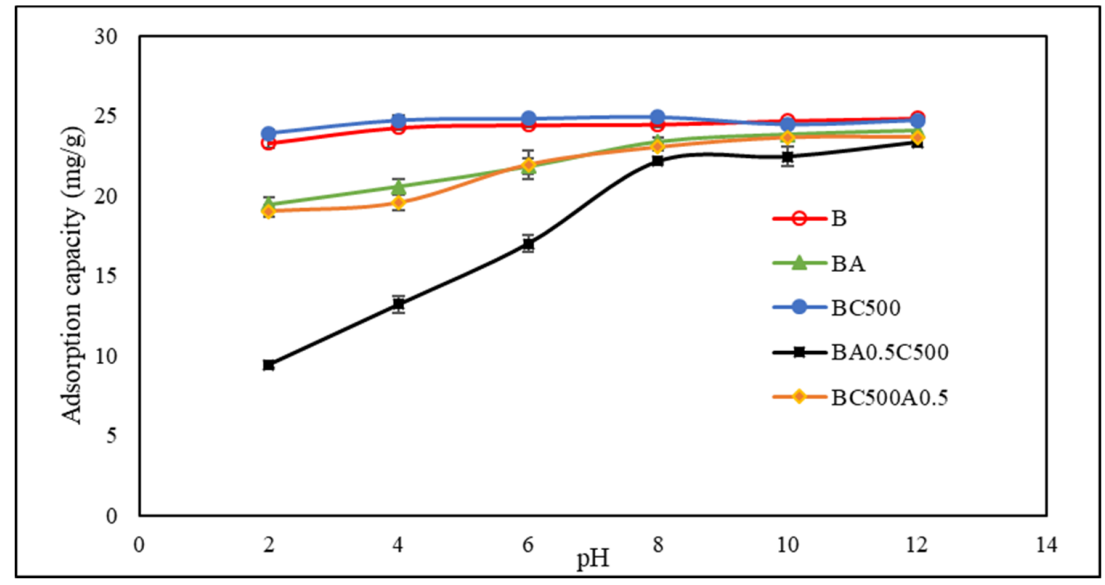

(a)

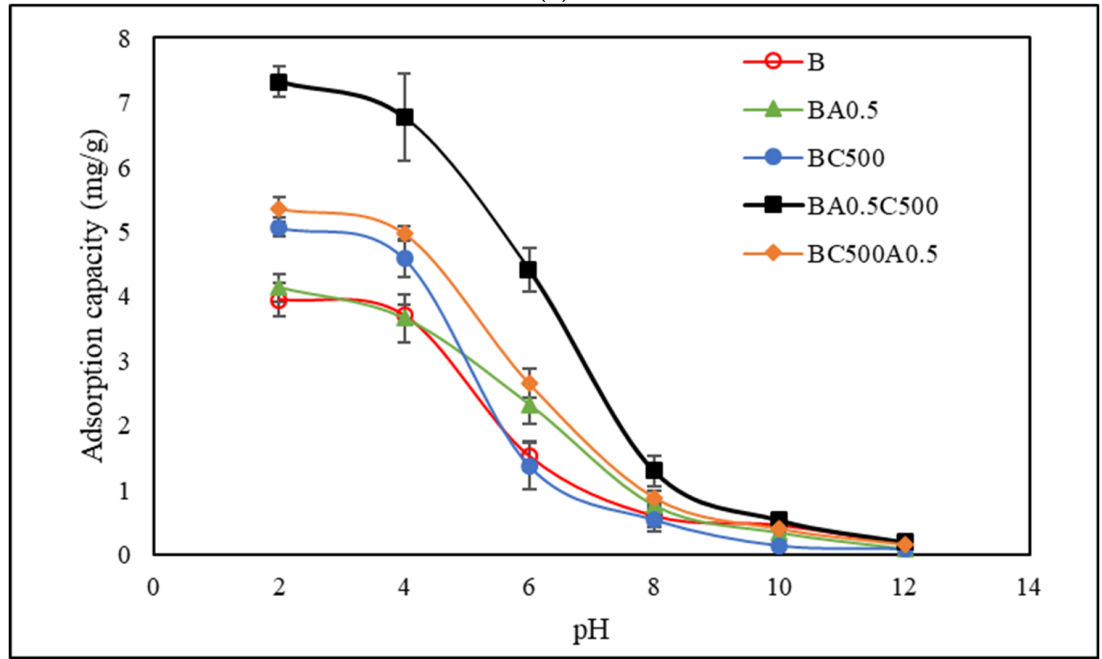

(b)

Figure 6. Cont. 


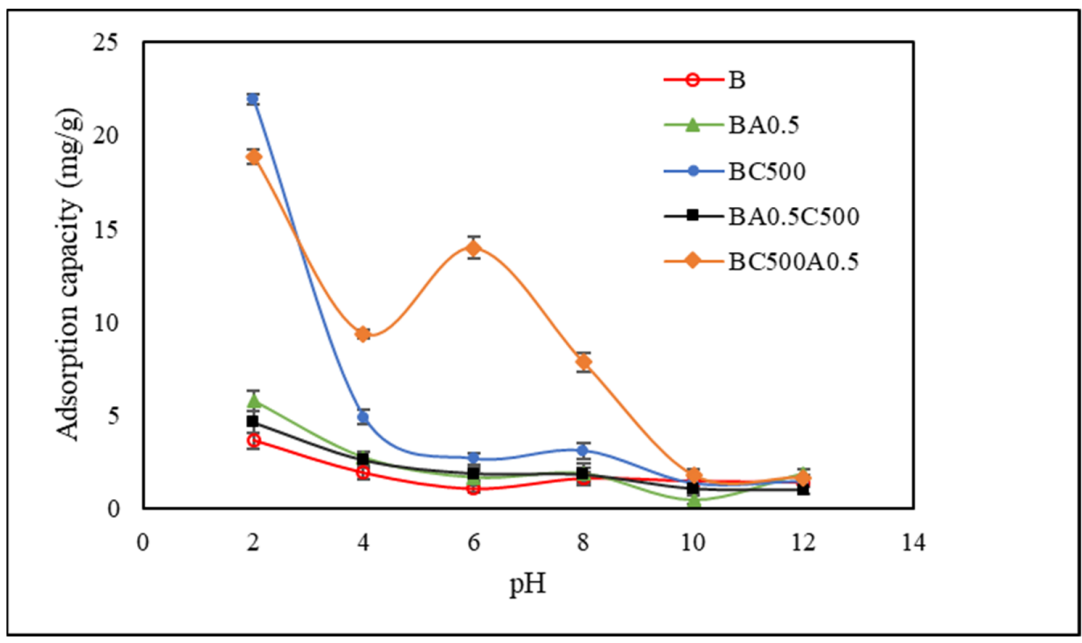

(c)

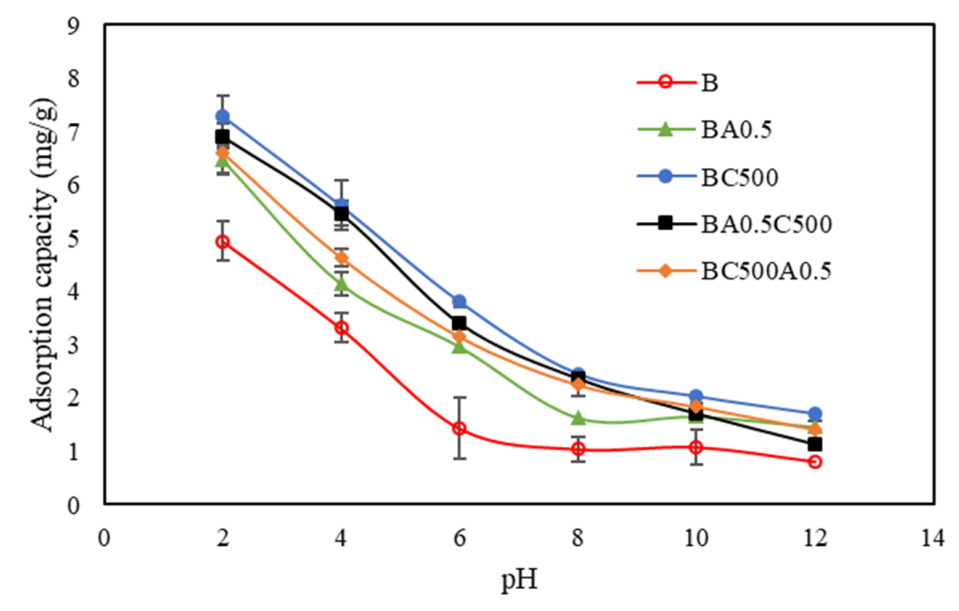

(d)

Figure 6. Adsorption capacity of modified and unmodified bentonite for paraquat (a); 2,4-D (b); atrazine (c); and diuron (d) at various $\mathrm{pH}$ and at $50 \mathrm{ppm}$.

In contrast to the case of 2,4-D adsorption (Figure 6b), 2,4-D has a pKa of 3.55; it can exist in both neutral and anionic form. At a $\mathrm{pH}$ of 3-6, an anionic form appears at around $22-99.5 \%$ in aqueous solution [44]. 2,4-D adsorption by $\mathrm{BA}_{0.5} \mathrm{C}_{500}$ is found to be the highest in the $\mathrm{pH}$ range of 2-6, due to the positively charged surface of $\mathrm{BA}_{0.5} \mathrm{C}_{500}$ (as in Table 4), preferring to absorb the anion form and including $\mathrm{BA}_{0.5} \mathrm{C}_{500}$ with the highest surface area. Thus, $\mathrm{BA}_{0.5} \mathrm{C}_{500}$ is an adsorbent suitable for 2,4-D. The lower adsorption capacity of 2,4-D with an increase in $\mathrm{pH}$ is probably due to the increased negative charge of the adsorbents.

Considering the case of atrazine adsorption by bentonite and modified bentonite shown in Figure $6 c$, atrazine is possibly in either protonated or neutral form depending on the solution $\mathrm{pH}$. At $\mathrm{pH}$ values approaching a $\mathrm{pKa}$ of atrazine $(\mathrm{pKa}=1.7)$, both protonated and neutral forms are present in the solution. Protonated atrazine preferentially adsorbs by cation exchange, while un-protonated form tends to adsorb on the active sites. According to the results of the adsorption in the range of $\mathrm{pH} 4-8$, the neutral form of atrazine seems to be the most preferential to $\mathrm{BC}_{500} \mathrm{~A}_{0.5}$. At $\mathrm{pH} 2.0, \mathrm{BC}_{500}$ exhibits the greatest atrazine adsorption capacity. One explanation is that at $\mathrm{pH} 2$, where atrazine exists in a neutral and protonated form, and the removal of atrazine would be through ion exchange and the adsorption mechanism. $\mathrm{BC}_{500}$ removes atrazine mainly through ion exchange due to its low surface area. Nonetheless, it has a lower CEC than bentonite, suggesting that the ion exchange process of cationic atrazine probably occurs efficiently at the edge and face of $\mathrm{BC}_{500}$ instead of at the interlayer spacing (like bentonite), in which a large molecule of 
atrazine is difficult to penetrate, causing very low adsorption for bentonite. The result of calcination might cause more exchangeable cations moving to the edge and face of $\mathrm{BC}_{500}$. Consequently, the cation exchange of atrazine is easier at these sites. In the case of adsorbents activated with acid $\left(\mathrm{BA}_{0.5} \mathrm{C}_{500}, \mathrm{BA}_{0 \cdot 5}\right.$, and $\left.\mathrm{BC}_{500} \mathrm{~A}_{0.5}\right)$, some partial cations are removed. Thus, these adsorbents show lower CEC values, causing a reduction in ion exchange.

However, these adsorbents contain high specific surface areas and a feature of $\mathrm{Al}$ Lewis-acid site, $\mathrm{Si}-\mathrm{OH}$ and $\mathrm{Si}-\mathrm{OH}_{2}{ }^{+}$groups, which are available for binding to both forms of atrazine. At $\mathrm{pH} 2$, however, the adsorbent of $\mathrm{BC}_{500} \mathrm{~A}_{0.5}$ still shows a high adsorption capacity in spite of having a smaller specific surface area (Table 5), suggesting that atrazine binds to BC500A0.5 through both ion exchange and the adsorption process. This may result from a small particle size with highly active sites at the edge and face of $\mathrm{BC}_{500} \mathrm{~A}_{0.5}$ which enhances the removal of atrazine. The feasible interaction of atrazine bound to the adsorbents is a formation of a Lewis acid-base complex from an Al Lewis-acid site and Lewis base from atrazine (lone pair of electron on nitrogen), including the formation of hydrogen bonds to $\mathrm{Si}-\mathrm{OH}$ and $\mathrm{Si}-\mathrm{OH}_{2}{ }^{+}$groups.

Table 5. Langmuir and Freundlich paraquat adsorption isotherm constants.

\begin{tabular}{|c|c|c|c|c|c|c|}
\hline \multirow{3}{*}{ Samples } & \multicolumn{3}{|c|}{ Langmuir } & \multicolumn{3}{|c|}{ Freundlich } \\
\hline & \multirow{2}{*}{$\frac{\mathrm{q}_{\mathrm{m}}}{\left(\mathrm{mg} \mathrm{g}^{-1}\right)}$} & \multirow{2}{*}{$\frac{\mathrm{K}_{\mathrm{L}}}{\left(\mathrm{L} \mathrm{mg}^{-1}\right)}$} & \multirow{2}{*}{$\mathbf{R}^{2}$} & \multirow{2}{*}{$\frac{K_{F}}{\left.g^{-1}\right) \cdot\left(\mathrm{L} \mathrm{mg}^{-1}\right)^{1 / n}}$} & \multirow{2}{*}{$\mathbf{n}$} & \multirow{2}{*}{$\mathbf{R}^{2}$} \\
\hline & & & & & & \\
\hline B & 4.76 & 18.77 & 0.9972 & 6.69 & 1.81 & 0.8977 \\
\hline $\mathrm{BA}_{0.5}$ & 1.75 & 100.39 & 0.9966 & 3.54 & 1.56 & 0.9266 \\
\hline $\mathrm{BC}_{500}$ & 3.58 & 23.26 & 0.9983 & 5.12 & 1.71 & 0.9101 \\
\hline $\mathrm{BA}_{0.5} \mathrm{C}_{500}$ & 0.85 & 52.63 & 0.9987 & 11.83 & 5.26 & 0.9726 \\
\hline $\mathrm{BC}_{500} \mathrm{~A}_{0.5}$ & 2.11 & 43.90 & 0.9986 & 2.44 & 1.43 & 0.8715 \\
\hline
\end{tabular}

The adsorptions of diuron are shown in Figure 6d. Diuron exists half in neutral form and half in cationic form at approximately $\mathrm{pH} 4$ [45]. The diuron adsorption is high for all adsorbents at low $\mathrm{pH}$ arising through the ion exchange process and the adsorption decreases with increasing $\mathrm{pH}$, possibly due to competition between excess $\mathrm{OH}^{-}$and adsorbate to interact with active sites. However, the high adsorption of diuron with $\mathrm{BC}_{500}$ and $\mathrm{BA}_{0.5} \mathrm{C}_{500}$ compared to the others may result from an increase in hydrophobicity (as mentioned in TG results) for both adsorbents to adsorb a more neutral form.

\subsubsection{Simultaneous Adsorption of Various Pesticides in Solutions}

The results of each pesticide adsorption (single-component) and simultaneous adsorptions of the four pesticides (quaternary-component) from aqueous solution onto all adsorbents at ambient temperature and at initial $\mathrm{pH}$ of solution $(6.5 \pm 0.5)$ without $\mathrm{pH}$ adjustment are shown in Figures 7 and 8, respectively. All adsorbents can remove $\mathrm{PQ}^{2+}$ from both single and quaternary-component systems. In the quaternary-component system, the adsorption of $\mathrm{PQ}^{2+}$ was slightly reduced compared with single-component due to the $\mathrm{PQ}^{2+}$ adsorption occurring mainly inside the interlayer space of the adsorbents. Accordingly, the other pesticides (atrazine diuron and 2,4-D) in the quaternary-component do not affect the adsorption of $\mathrm{PQ}^{2+}$ in the interlayer space of the adsorbents. The 2,4-D adsorption is decreased, except for $\mathrm{BA}_{0.5} \mathrm{C}_{500}$ with the same adsorption capacity as in a single component, possibly due to the positive zeta potential of $\mathrm{BA}_{0.5} \mathrm{C}_{500}$ surface (see Table 4) which provides an electrostatic attraction from the positively charged surface and 2,4-D (anion pesticide). Atrazine still prefers $\mathrm{BC}_{500} \mathrm{~A}_{0.5}$ in quaternary-component, but the adsorption capacity is lower than that in a single-component due to the limited number of active sites (as mentioned in Topic 2.6). In contrast to diuron (non-polar pesticide), it was found that the adsorption of diuron in the quaternary-component was higher than that in the single-component. This could be explained by the simultaneous adsorption; $\mathrm{PQ}^{2+}$ adsorbed at the surface of the adsorbents can act as an additional active site, which 
is competent to attach diuron through the interaction between dipole ( $\mathrm{C}=\mathrm{O}$ of diuron) and cation $\left(\mathrm{PQ}^{2+}\right)$. Therefore, the presence of $\mathrm{PQ}^{2+}$ in quaternary-component enhances diuron adsorption. The maximum total values of the simultaneous adsorption of various pesticides from aqueous solution belong to $\mathrm{BC}_{500} \mathrm{~A}_{0.5}$, indicating that $\mathrm{BC}_{500} \mathrm{~A}_{0.5}$ is the most suitable for the simultaneous removal of different types of pesticides. Hence, it could be regarded as an effectively multifunctional adsorbent.

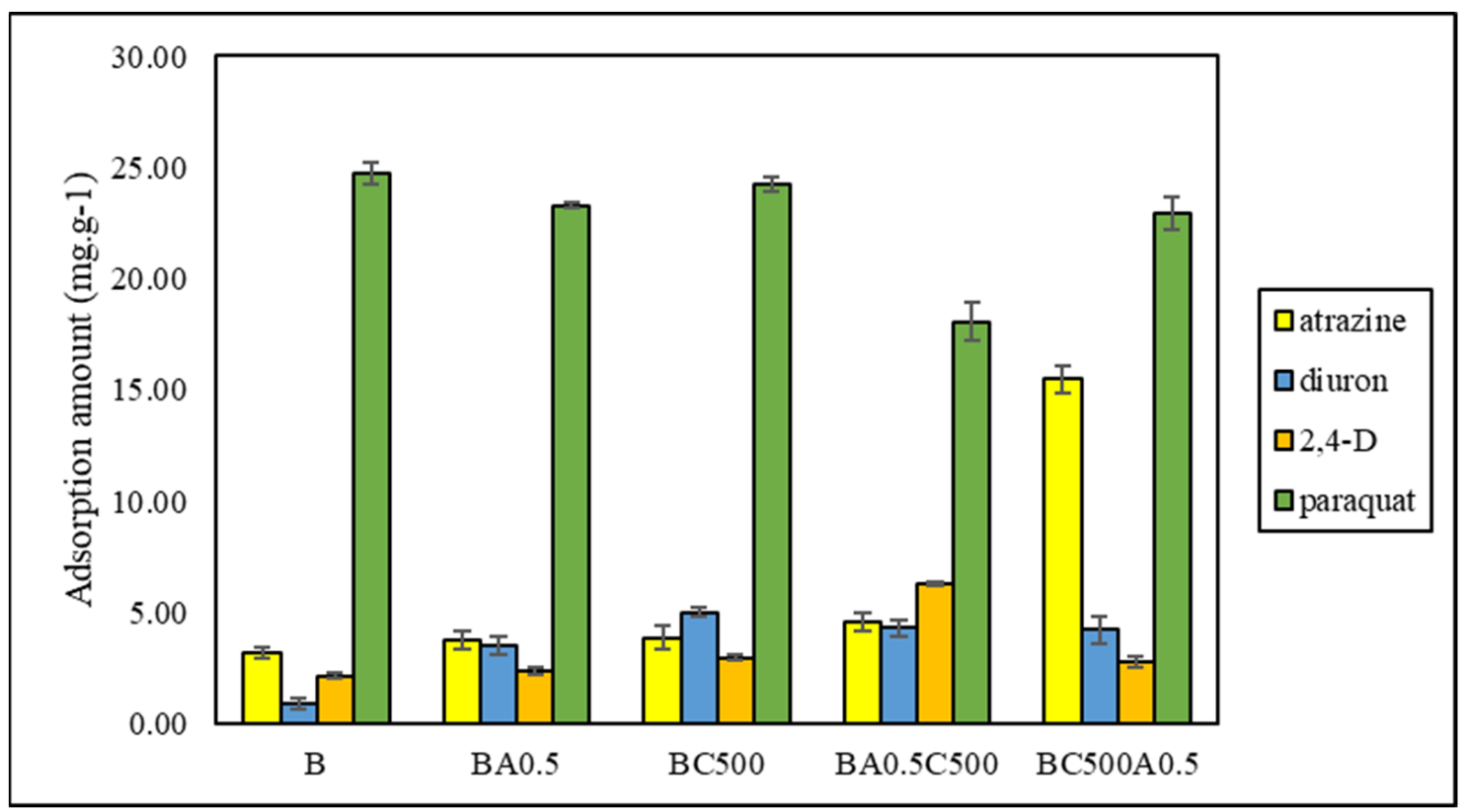

Figure 7. Adsorption of single-component pesticide with a concentration of $50 \mathrm{mg} \mathrm{L}^{-1}$ at $\mathrm{pH} 6.5 \pm 0.5$ onto bentonite and modified bentonite.

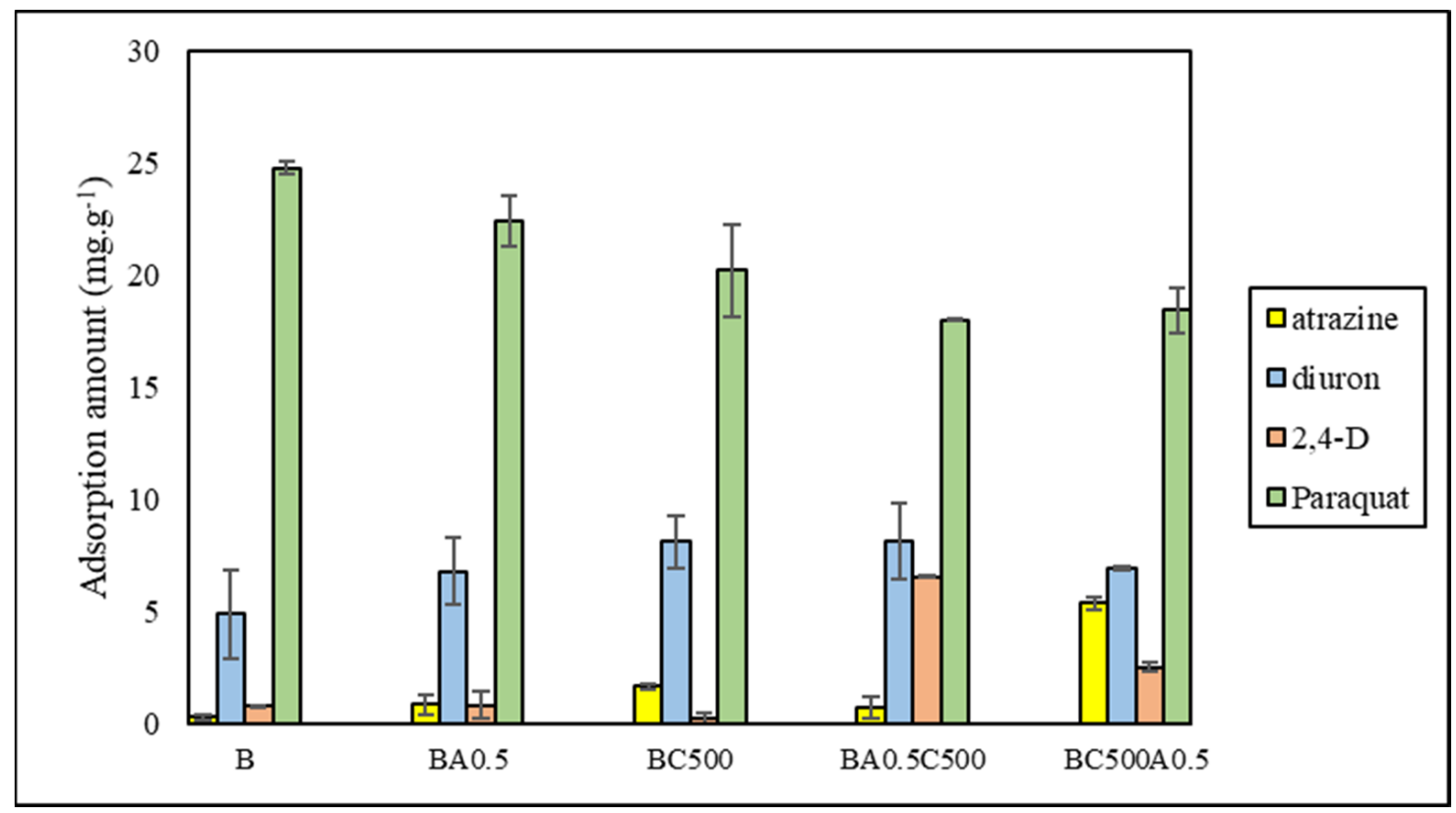

Figure 8. Adsorption of quaternary-component pesticides (with each pesticide $50 \mathrm{mg} \mathrm{L}^{-1}$ ) at $\mathrm{pH} 6.5 \pm 0.5$ onto bentonite and modified bentonite. 


\subsection{Adsorption Isotherms}

Pesticide adsorption data were evaluated with Langmuir and Freundlich isotherm models. The Langmuir isotherm was used to determine the monolayer and homogeneous adsorption on a surface [33]. The Freundlich isotherm is an empirical equation that assumes the adsorption surface is heterogeneous during the course of the adsorption process or multilayer sorption [46].

Linear forms of the Langmuir and Freundlich adsorption isotherms shown in Equations (2) and (3), respectively, were applied to quantitatively evaluate sorption performance:

$$
\frac{\mathrm{C}_{\mathrm{e}}}{\mathrm{q}_{\mathrm{e}}}=\frac{\mathrm{C}_{\mathrm{e}}}{\mathrm{q}_{\mathrm{m}}}+\frac{1}{\mathrm{q}_{\mathrm{m}} \mathrm{K}_{\mathrm{L}}}
$$

where $\mathrm{C}_{\mathrm{e}}$ is the equilibrium concentration of the pesticide in a bulk solution $\left(\mathrm{mg} \mathrm{L}^{-1}\right), \mathrm{q}_{\mathrm{e}}$ is the amount of pesticide adsorbed per unit mass of adsorbent at equilibrium $\left(\mathrm{mg} \mathrm{g}^{-1}\right)$, $\mathrm{q}_{\mathrm{m}}$ is the maximum adsorption capacity $\left(\mathrm{mg} \mathrm{g}^{-1}\right)$, and $\mathrm{K}_{\mathrm{L}}$ is the Langmuir constant ( $\mathrm{L}$ $\left.\mathrm{mg}^{-1}\right)$ :

$$
\log \mathrm{q}_{\mathrm{e}}=\log \mathrm{K}_{\mathrm{F}}+\frac{1}{\mathrm{n}} \log \mathrm{C}_{\mathrm{e}}
$$

where $\mathrm{K}_{\mathrm{F}}$ (units: $\left.\left(\mathrm{mg} \mathrm{g}^{-1}\right)\left(\mathrm{L} \mathrm{mg}^{-1}\right)^{1 / \mathrm{n}}\right)$ is the Freundlich constant, a characteristic of the system. The constant is indicative of the relative adsorption capacity of adsorption, while the term $1 / \mathrm{n}$ represents adsorption intensity. The detailed parameters of these different isotherm equations are also listed in Tables 5-8. All correlation coefficients $\left(R^{2}\right)$ exceed 0.9, suggesting that all models fit the experimental results well.

The atrazine adsorption at $\mathrm{pH} 6$ fits the Langmuir model better than the Freundlich model and the calculated maximum monolayer $\left(\mathrm{q}_{\mathrm{m}}\right)$ of adsorbed atrazine on $\mathrm{BC}_{500} \mathrm{~A}_{0.5}$ is higher than the other adsorbents. Moreover, neutral diuron adsorption at $\mathrm{pH} 6$ shows the best fit to the Langmuir model compared to the Freundlich isotherm model for $\mathrm{BC}_{500}$, $\mathrm{BA}_{0.5} \mathrm{C}_{500}$, and $\mathrm{BC}_{500} \mathrm{~A}_{0.5}$. Moreover, diuron at $\mathrm{pH} 6$ was preferentially adsorbed on bentonite and the modified bentonite surfaces via monolayer adsorption. In the case of bentonite and $\mathrm{BA}_{0.5}$ for diuron adsorption at $\mathrm{pH} 6$, it is fit both for the Langmuir and the Freundlich isotherm models. In the case of anion and cation, pesticides would be described with 2,4-D and paraquat pesticide, respectively. The data for 2,4-D adsorption at $\mathrm{pH} 6$ the adsorption is only anion 2,4-D. The $\mathrm{R}^{2}$ value confirms the adsorption equilibrium data fitted well with the Langmuir model. The $\mathrm{q}_{\mathrm{m}}$ of 2,4-D adsorbed on $\mathrm{BA}_{0.5} \mathrm{C}_{500}$ is higher than that on the other adsorbents in this experiment. Moreover, the adsorption isotherm for the removal of paraquat from aqueous solution, the $\mathrm{R}^{2}$ values from the Langmuir isotherm of all adsorbents are close to 1, indicating that the surface of each adsorbent is unique for paraquat adsorption in monolayer adsorption.

We selected the adsorbent that is capable of adsorbing the maximum amount of each pesticide to study the adsorption isotherms. The adsorption isotherms of bentonite and the selected modified bentonite at 303,313 , and $323 \mathrm{~K}$ are shown in the supplementary information in Figure S3 and Tables 9-12. The results indicate that atrazine, diuron and 2,4-D adsorptions increase with higher temperatures, being the cause of increased pesticide diffusion rates onto the active sites of the adsorbents, but with little significant effect for paraquat adsorption. 
Table 6. Langmuir and Freundlich 2,4-D adsorption isotherm constants.

\begin{tabular}{|c|c|c|c|c|c|c|}
\hline \multirow{3}{*}{ Samples } & \multicolumn{3}{|c|}{ Langmuir } & \multicolumn{3}{|c|}{ Freundlich } \\
\hline & \multirow{2}{*}{$\frac{q_{m}}{\left(m g g^{-1}\right)}$} & \multirow{2}{*}{$\frac{\mathrm{K}_{\mathrm{L}}}{\left(\mathrm{L} \mathrm{mg}^{-1}\right)}$} & \multirow{2}{*}{$\mathbf{R}^{2}$} & $\mathbf{K}_{\mathbf{F}}$ & \multirow{2}{*}{$\mathbf{n}$} & \multirow{2}{*}{$\mathbf{R}^{2}$} \\
\hline & & & & $\left(\mathrm{mg} \mathrm{g}^{-1}\right) .\left(\mathrm{L} \mathrm{mg}^{-1}\right)^{1 / n}$ & & \\
\hline B & 0.32 & 12.19 & 0.9968 & 1.26 & 4.32 & 0.9701 \\
\hline $\mathrm{BA}_{0.5}$ & 0.31 & 14.74 & 0.9976 & 0.96 & 3.06 & 0.9906 \\
\hline $\mathrm{BC}_{500}$ & 0.28 & 15.24 & 0.9972 & 1.17 & 3.06 & 0.9479 \\
\hline $\mathrm{BA}_{0.5} \mathrm{C}_{500}$ & 0.39 & 16.57 & 0.9925 & 0.58 & 1.80 & 0.9842 \\
\hline $\mathrm{BC}_{500} \mathrm{~A}_{0.5}$ & 0.31 & 14.74 & 0.9986 & 1.22 & 3.70 & 0.9946 \\
\hline
\end{tabular}

Table 7. Langmuir and Freundlich atrazine adsorption isotherm constants.

\begin{tabular}{|c|c|c|c|c|c|c|}
\hline \multirow{3}{*}{ Samples } & \multicolumn{3}{|c|}{ Langmuir } & \multicolumn{3}{|c|}{ Freundlich } \\
\hline & \multirow{2}{*}{$\frac{\mathrm{q}_{\mathrm{m}}}{\left(\mathrm{mg} \mathrm{g}^{-1}\right)}$} & \multirow{2}{*}{$\begin{array}{c}\mathrm{K}_{\mathrm{L}} \\
\left(\mathrm{L} \mathrm{mg}^{-1}\right)\end{array}$} & \multirow{2}{*}{$\mathbf{R}^{2}$} & $\mathbf{K}_{\mathbf{F}}$ & \multirow{2}{*}{$\mathbf{n}$} & \multirow{2}{*}{$\mathbf{R}^{2}$} \\
\hline & & & & $\left(\mathrm{mg} \mathrm{g}^{-1}\right) \cdot\left(\mathrm{L} \mathrm{mg}^{-1}\right)^{1 / n}$ & & \\
\hline B & 3.18 & 1.01 & 0.9970 & 0.38 & 2.52 & 0.9822 \\
\hline $\mathrm{BA}_{0.5}$ & 6.37 & 0.52 & 0.9993 & 0.28 & 1.99 & 0.9563 \\
\hline $\mathrm{BC}_{500}$ & 4.52 & 2.05 & 0.9920 & 0.36 & 2.38 & 0.9795 \\
\hline $\mathrm{BA}_{0.5} \mathrm{C}_{500}$ & 5.22 & 0.53 & 0.9982 & 0.31 & 2.14 & 0.9651 \\
\hline $\mathrm{BC}_{500} \mathrm{~A}_{0.5}$ & 15.87 & 3.64 & 0.9970 & 0.31 & 2.04 & 0.9902 \\
\hline
\end{tabular}

Table 8. Langmuir and Freundlich diuron adsorption isotherm constants.

\begin{tabular}{|c|c|c|c|c|c|c|}
\hline \multirow{3}{*}{ Samples } & \multicolumn{3}{|c|}{ Langmuir } & \multicolumn{3}{|c|}{ Freundlich } \\
\hline & \multirow{2}{*}{$\frac{\mathrm{q}_{\mathrm{m}}}{\left(\mathrm{mg} \mathrm{g}^{-1}\right)}$} & \multirow{2}{*}{$\frac{\mathrm{K}_{\mathrm{L}}}{\left(\mathrm{L} \mathrm{mg}^{-1}\right)}$} & \multirow{2}{*}{$\mathbf{R}^{2}$} & $\mathbf{K}_{\mathbf{F}}$ & \multirow{2}{*}{$\mathbf{n}$} & \multirow{2}{*}{$\mathbf{R}^{2}$} \\
\hline & & & & $\left(\mathrm{mg} \mathrm{g}^{-1}\right) .\left(\mathrm{L} \mathrm{mg}^{-1}\right)^{1 / n}$ & & \\
\hline B & 0.17 & 31.71 & 0.9820 & 0.39 & 1.87 & 0.9703 \\
\hline $\mathrm{BA}_{0.5}$ & 0.88 & 8.01 & 0.9327 & 2.08 & 3.61 & 0.9668 \\
\hline $\mathrm{BC}_{500}$ & 1.92 & 5.05 & 0.9541 & 4.01 & 5.08 & 0.8312 \\
\hline $\mathrm{BA}_{0.5} \mathrm{C}_{500}$ & 1.24 & 7.41 & 0.9715 & 3.01 & 4.04 & 0.8983 \\
\hline $\mathrm{BC}_{500} \mathrm{~A}_{0.5}$ & 1.19 & 6.38 & 0.9262 & 2.82 & 4.55 & 0.8886 \\
\hline
\end{tabular}

The maximum adsorption monolayer capacity $\left(\mathrm{q}_{\mathrm{m}}\right)$ and the Langmuir constant $\left(\mathrm{K}_{\mathrm{L}}\right)$ calculated from the slope and intercept of the linear plot, are shown in Tables 9-12.

Table 9. Parameters for adsorption of atrazine on bentonite and $\mathrm{BC}_{500} \mathrm{~A}_{0.5}$.

\begin{tabular}{ccccc}
\hline \multirow{2}{*}{ Samples } & \multirow{2}{*}{ Temperature (K) } & \multicolumn{3}{c}{ Langmuir Isotherm } \\
\cline { 3 - 5 } & & $\mathbf{q}_{\mathbf{m}} \mathbf{( \mathbf { m g ~ g } ^ { - \mathbf { 1 } } )}$ & $\left.\mathbf{K}_{\mathbf{L}} \mathbf{~} \mathbf{~}^{-\mathbf{1}}\right)$ & $\mathbf{R}^{\mathbf{2}}$ \\
\hline \multirow{2}{*}{ Bentonite } & 303 & 3.38 & 6.15 & 0.9915 \\
& 313 & 3.89 & 5.53 & 0.9964 \\
& 323 & 4.19 & 6.65 & 0.9990 \\
\hline $\mathrm{BC}_{500} \mathrm{~A}_{0.5}$ & 303 & 16.64 & 452.14 & 0.9992 \\
& 313 & 17.15 & 632.94 & 0.9995 \\
& 323 & 18.35 & 955.66 & 0.9986 \\
\hline
\end{tabular}


Table 10. Parameters for adsorption of diuron on bentonite and $\mathrm{BC}_{500}$.

\begin{tabular}{ccccc}
\hline \multirow{2}{*}{ Samples } & \multirow{2}{*}{ Temperature (K) } & \multicolumn{3}{c}{ Langmuir Isotherm } \\
\cline { 3 - 5 } & & $\mathbf{q}_{\mathbf{m}} \mathbf{( \mathbf { m g ~ g } ^ { - \mathbf { 1 } } )}$ & $\mathbf{K}_{\mathbf{L}} \mathbf{( \mathbf { M } ^ { - \mathbf { 1 } } )}$ & $\mathbf{R}^{\mathbf{2}}$ \\
\hline \multirow{2}{*}{ Bentonite } & 303 & 5.12 & 0.83 & 0.9580 \\
& 313 & 5.10 & 1.06 & 0.9920 \\
& 323 & 5.45 & 1.30 & 0.9608 \\
\hline $\mathrm{BC}_{500}$ & 303 & 10.34 & 11.85 & 0.8725 \\
& 313 & 11.27 & 13.87 & 0.8531 \\
& 323 & 11.95 & 14.86 & 0.8935 \\
\hline
\end{tabular}

Table 11. Parameters for adsorption of 2,4-D on bentonite and $\mathrm{BA}_{0.5} \mathrm{C}_{500}$.

\begin{tabular}{ccccc}
\hline \multirow{2}{*}{ Samples } & \multirow{2}{*}{ Temperature (K) } & \multicolumn{3}{c}{ Langmuir Isotherm } \\
\cline { 3 - 5 } & & $\mathbf{q}_{\mathbf{m}} \mathbf{( \mathbf { m g ~ g } ^ { - \mathbf { 1 } } )}$ & $\mathbf{K}_{\mathbf{L}} \mathbf{( \mathbf { M } ^ { - \mathbf { 1 } } )}$ & $\mathbf{R}^{\mathbf{2}}$ \\
\hline \multirow{2}{*}{ Bentonite } & 303 & 4.07 & 1.29 & 0.9829 \\
& 313 & 4.50 & 1.17 & 0.9618 \\
& 323 & 4.40 & 1.85 & 0.9643 \\
\hline $\mathrm{BA}_{0.5} \mathrm{C}_{500}$ & 303 & 7.37 & 2.66 & 0.9662 \\
& 313 & 8.55 & 8.64 & 0.9990 \\
& 323 & 8.66 & 10.45 & 0.9981 \\
\hline
\end{tabular}

Table 12. Parameters for adsorption of paraquat on bentonite and $\mathrm{BC}_{500}$.

\begin{tabular}{ccccc}
\hline \multirow{2}{*}{ Samples } & \multirow{2}{*}{ Temperature (K) } & \multicolumn{3}{c}{ Langmuir Isotherm } \\
\cline { 3 - 5 } & & $\mathbf{q}_{\mathbf{m}} \mathbf{( \mathbf { m g ~ g } ^ { - \mathbf { 1 } } )}$ & $\mathbf{K}_{\mathbf{L}} \mathbf{( \mathbf { M } ^ { - \mathbf { 1 } } )}$ & $\mathbf{R}^{\mathbf{2}}$ \\
\hline \multirow{2}{*}{ Bentonite } & 303 & 94.34 & 480.83 & 0.9966 \\
& 313 & 92.59 & 563.90 & 0.9970 \\
& 323 & 87.72 & 4023.82 & 0.9697 \\
\hline $\mathrm{BC}_{500}$ & 303 & 92.59 & 328.58 & 0.9959 \\
& 313 & 84.03 & 1446.36 & 0.9671 \\
& 323 & 84.03 & 1446.36 & 0.9671 \\
\hline
\end{tabular}

Enthalpy $(\Delta \mathrm{H})$, entropy $(\Delta S)$ and free energy $(\Delta \mathrm{G})$ changes explain the thermodynamic data for the adsorption process, which were calculated by

$$
\Delta \mathrm{G}^{\circ}=-\mathrm{RT} \ln \mathrm{K}_{\mathrm{L}}
$$

where $\mathrm{R}$ is the gas constant $\left(8.314 \mathrm{~J} \mathrm{~mol}^{-1} \mathrm{k}^{-1}\right)$; $\mathrm{T}$ is temperature $(\mathrm{K})$ and $\mathrm{K}_{\mathrm{L}}$ is adsorption constant in the Langmuir isotherm. The values of $\Delta \mathrm{H}^{\circ}$ and $\Delta \mathrm{S}^{\circ}$ can be calculated from the slope and intercept of the linear variation of $\ln K_{L}$ with reciprocal of temperature $(1 / T)$ as in the following equation:

$$
\ln \mathrm{K}_{\mathrm{L}}=-\frac{\Delta \mathrm{H}^{\circ}}{\mathrm{RT}}+\frac{\Delta \mathrm{S}^{\circ}}{\mathrm{R}}
$$

The thermodynamic parameters of the system: Gibbs free energy change $\left(\Delta G^{\circ}\right)$, enthalpy change $\left(\Delta \mathrm{H}^{\circ}\right)$, and entropy change $\left(\Delta \mathrm{S}^{\circ}\right)$, are shown in the supplementary information in Tables S2-S5; the free energy values at temperatures $303 \mathrm{~K}, 313 \mathrm{~K}$ and $323 \mathrm{~K}$ in the adsorption of pesticides are negative in all cases, demonstrating the spontaneous nature of the process. $\Delta \mathrm{H}^{\circ}$ values are positive for all of the pesticides, showing the endothermic nature of the adsorption process. $\Delta \mathrm{S}^{\circ}$ values are also reported; positive values suggest that the organisation of the adsorbate in the solid-solution interface becomes more random. 


\subsection{Kinetic Experiments}

Kinetics studies on the adsorption of pesticide onto bentonite and modified bentonites were performed. The results are shown in Figure 9. Measurements were made using $20 \mathrm{mg}$ adsorbent at $30^{\circ} \mathrm{C}$, with atrazine concentrations of $50 \mathrm{mg} \mathrm{L}^{-1}$. All adsorbents exhibited a high affinity for atrazine during the first $50 \mathrm{~min}$, and equilibrium was reached within $200 \mathrm{~min}$.

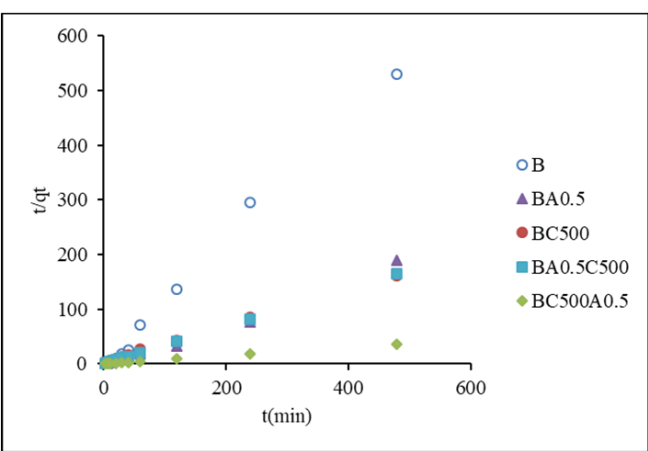

(a)

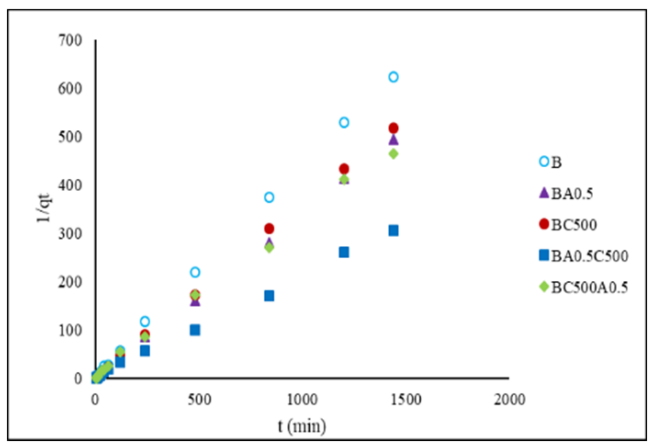

(c)

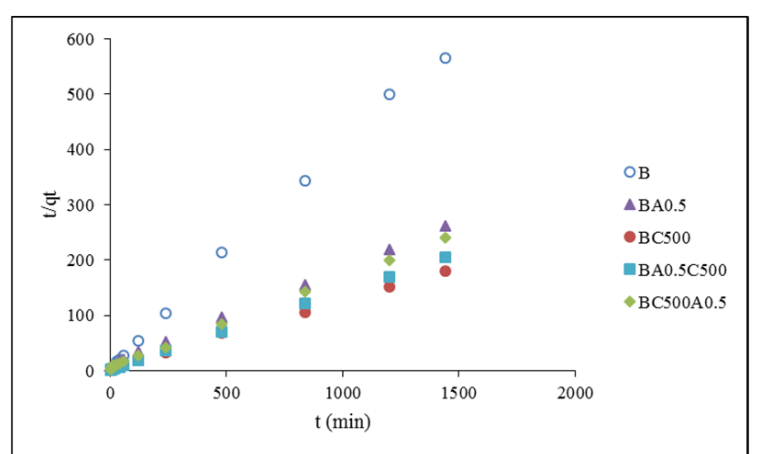

(b)

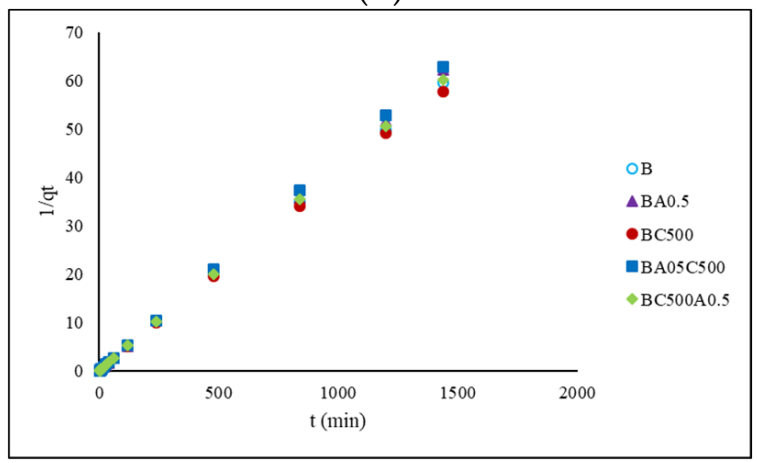

(d)

Figure 9. Pseudo-second order plots of atrazine (a); diuron (b); 2,4-D (c); and paraquat (d) adsorption onto bentonite and modified bentonites.

Pseudo-first and pseudo-second-order models were employed to correlate the kinetics data. A pseudo-first-order kinetics adsorption model was suggested for the sorption of solid/liquid systems and is expressed in an integrated and linear form in Equation (6) [47]:

$$
\log \left(q_{e}-q_{t}\right)=\log q_{e}-\frac{k_{1}}{2.303} t
$$

where $\mathrm{k}_{1}$ is the adsorption rate constant $\left(\mathrm{min}^{-1}\right), \mathrm{q}_{\mathrm{e}}$ and $\mathrm{q}_{\mathrm{t}}$ are the atrazine adsorption loadings $\left(\mathrm{mg} \mathrm{g}^{-1}\right)$ at equilibrium and at time $\mathrm{t}(\mathrm{min})$, respectively. If the pseudo-first-order kinetics is applicable, a plot of $\log \left(\mathrm{q}_{\mathrm{e}}-\mathrm{q}_{\mathrm{t}}\right)$ versus $\mathrm{t}$ should provide a straight line, from which $\mathrm{k}_{1}$ and the predicted value for $\mathrm{q}_{\mathrm{e}}$ can be determined from the slope and intercept of the plot.

The pseudo-second-order kinetics model is expressed by Equation (7) [48]:

$$
\frac{\mathrm{t}}{\mathrm{q}_{\mathrm{t}}}=\frac{1}{\mathrm{q}_{\mathrm{e}}} \mathrm{t}+\frac{1}{\mathrm{k}_{2} \mathrm{q}_{\mathrm{e}}^{2}}
$$

where $\mathrm{k}_{2}\left(\mathrm{~g} \mathrm{mg}^{-1} \mathrm{~min}^{-1}\right)$ is the pseudo-second-order adsorption rate constant. A plot of $t / q_{t}$ against (Figure 9) yields a straight line, from which the rate constant $k_{2}$ and $\mathrm{q}_{\mathrm{e}}$ can be calculated. The pseudo-second-order model is based on the assumption that the rate-limiting step may be chemisorption, which involves valence forces by electron sharing or electron exchange between the adsorbent and the adsorbate. Tables S6-S9 in 
the supplementary information shows maximum adsorption capacities of $\mathrm{q}_{\mathrm{e}}, \mathrm{k}_{1}, \mathrm{k}_{2}$ and the correlation coefficient $\mathrm{R}^{2}$, calculated from the pseudo-first and pseudo-second-order models. The maximum adsorption capacity, $\mathrm{q}_{\mathrm{e}}$, calculated from the pseudo-second-order equation, is in accordance with the experimentally determined values. The $\mathrm{R}^{2}$ values for the pseudo-second-order are greater than those in the pseudo-first-order model. These results suggest that adsorption follows the pseudo-second-order model. The indication is that the adsorption of pesticides occurs by a chemisorption mechanism between pesticide and adsorbent by innersphere complexes.

The Langmuir maximum adsorption capacity for the pesticides obtained from this work was compared with other reports from the literature. Table 13 confirms that the efficiency of bentonite and modified bentonite is similar to that of the other adsorbents, but the adsorbent of $\mathrm{BC}_{500} \mathrm{~A}_{0.5}$ is the best for atrazine removal due to the smallest particle size and the highly active region of $\mathrm{Al}$ Lewis-acid site which is available for easily bound atrazine via a Lewis acid-base complex. Therefore, the fixation of atrazine in $\mathrm{BC}_{500} \mathrm{~A}_{0.5}$ is more promoted than zeoliteX, biochars (SBB) and iron nanoparticles (INPs). While ion exchange is a primary process in removing cationic pesticide (paraquat), bentonite is therefore more efficient than diatomaceous earth. For diuron adsorption, $\mathrm{BC}_{500}$ is considered a preferred diuron for hydrophobic interaction that $\mathrm{BC}_{500}$ provides high hydrophobic space. Consequently, it shows a similar result to using activated carbon.

Table 13. Comparison of $\mathrm{q}_{\mathrm{m}}$ values from the Langmuir isotherm model of adsorbents and modified adsorbents for the removal of pesticides.

\begin{tabular}{|c|c|c|c|c|}
\hline Pesticide & Absorbents & $\mathrm{q}_{\mathrm{m}}$ & $\mathrm{pH}$ & Reference \\
\hline \multirow[t]{5}{*}{ Atrazine } & Zeolite-X & $\mathrm{q}_{\mathrm{m}}=11.86 \mathrm{mg} \mathrm{g}^{-1}$ & Not adjust & {$[2]$} \\
\hline & Biochars (SBB) & $\mathrm{qm}_{\mathrm{m}}=3.05 \mathrm{mg} \mathrm{g}^{-1}$ & & [46] \\
\hline & $\begin{array}{l}\text { carbon nanotubes } \\
\text { (MWCNTs-O) }\end{array}$ & $\mathrm{q}_{\mathrm{e}}=17.35 \mathrm{mg} \mathrm{g}^{-1}$ & 6 & [9] \\
\hline & Iron nanoparticles (INPs) & $\mathrm{q}_{\mathrm{m}}=11.76 \mu \mathrm{g} \mathrm{g}^{-1}$ & 4.5 & [49] \\
\hline & $\begin{array}{c}\text { Combination with Heat } 500^{\circ} \mathrm{C} \text { and activated } \\
0.5 \mathrm{HCl} \text { on Bentonite }\left(\mathrm{BC}_{500} \mathrm{~A}_{0.5}\right)\end{array}$ & $\mathrm{q}_{\mathrm{m}}=15.87 \mathrm{mg} \mathrm{g}^{-1}$ & 6.5 & This work \\
\hline \multirow[t]{3}{*}{ Diuron } & Activated carbon & $\mathrm{q}_{\mathrm{m}}=0.97 \mathrm{mmol} \mathrm{g}^{-1}$ & & [50] \\
\hline & CTA-TixHy-montm & $\mathrm{q}_{\mathrm{e}, \exp }=3.08 \mathrm{mg} \mathrm{g}^{-1}$ & & [45] \\
\hline & Heat treatment $\left(500^{\circ} \mathrm{C}\right)$ of bentonite $\left(\mathrm{BC}_{500}\right)$ & $\mathrm{q}_{\mathrm{m}}=1.92 \mathrm{mg} \mathrm{g}^{-1}$ & 6.5 & This work \\
\hline \multirow[t]{2}{*}{$2,4-\mathrm{D}$} & Graphene (FGN) & $\mathrm{q}_{\mathrm{e}}=19.95 \mathrm{mg} \mathrm{g}^{-1}$ & & [51] \\
\hline & $\begin{array}{c}\text { Combination with Heat } 500^{\circ} \mathrm{C} \text { and activated } \\
0.5 \mathrm{HCl} \text { on Bentonite }\left(\mathrm{BA}_{0.5} \mathrm{C}_{500}\right)\end{array}$ & $\begin{array}{c}\mathrm{q}_{\mathrm{m}}=0.39 \\
\mathrm{q}_{\mathrm{e}, \exp }=6.25 \mathrm{mg} \mathrm{g}^{-1}\end{array}$ & 6.5 & This work \\
\hline \multirow[t]{2}{*}{ Paraquat } & Treated diatomaceous earth & $\mathrm{q}_{\mathrm{m}}=17.54 \mathrm{mg} \mathrm{g}^{-1}$ & & [52] \\
\hline & Bentonite & $\mathrm{q}_{\mathrm{m}}=94.34 \mathrm{mg} \mathrm{g}^{-1}$ & 6.5 & This work \\
\hline
\end{tabular}

\section{Conclusions}

Bentonite was modified by either acid, heat, or both for the removal of different types of pesticides from an aqueous solution. It was found that $\mathrm{BC}_{500} \mathrm{~A}_{0.5}$ is the best and specific to atrazine adsorption with a very large amount compared to other adsorbents as a result of its small particle size with high edges and faces containing a high number of active sites (Al Lewis-acid sites, $\mathrm{Si}-\mathrm{OH}$, and $\mathrm{Si}-\mathrm{OH}_{2}{ }^{+}$groups). It is remarkable that $\mathrm{BC}_{500} \mathrm{~A}_{0.5}$ is highly specific in the adsorption of atrazine mainly due to participation and strong interaction between a lone pair electron on the nitrogen of the pesticide to $\mathrm{Al}$ Lewis-acid site of the adsorbent and additional moderate interaction is hydrogen bond formation of amine groups to $\mathrm{Si}-\mathrm{OH}$ and $\mathrm{Si}-\mathrm{OH}_{2}{ }^{+}$groups. $\mathrm{BC}_{500}$ shows higher diuron adsorption than the others adsorbent due to its high hydrophobicity in siloxanes; consequently, the interaction of $\mathrm{BC}_{500}$ and diuron maybe mainly hydrophobic. Additionally, $\mathrm{BA}_{0.5} \mathrm{C}_{500}$ is suitable for 2,4-D. The 2,4-D-adsorption may be induced by the positive zeta potential 
compensation indicating an interaction of anionic 2,4-D and the positively charged surface of the adsorbent.

Finally, it seems apparent that high paraquat adsorption capacity was found for all adsorbents. However, bentonite is the most favourite for paraquat as a result of the main removal of paraquat through ion exchange which is easily occurring due to a small size of paraquat and bentonite presents a high value of $C E C$, whereas $B_{0.5} C_{500}$ showed the lowest capacity because of $\mathrm{BA}_{0.5} \mathrm{C}_{500}$ with low $\mathrm{CEC}$ and swelling. $\mathrm{BC}_{500} \mathrm{~A}_{0.5}$ was recently developed by combining steps of bentonite for simultaneous pesticide removal from an aqueous solution, because it could remove a higher total amount of pesticides than the other adsorbents, indicating that it could be used as a good multifunctional adsorbent. The adsorption of all pesticides fits well with the Langmuir adsorption model compared to the Freundlich model, and the adsorption kinetics follow a pseudo-second order (chemisorption). The thermodynamic parameters of the pesticide adsorption, such as Gibbs free energy $\left(\Delta \mathrm{G}^{\circ}\right)$, enthalpy $\left(\Delta \mathrm{H}^{\circ}\right)$ and entropy $\left(\Delta \mathrm{S}^{\circ}\right)$ were also calculated, and the parameter values are reported in spontaneous and endothermic processes. This research demonstrated that the treatment of bentonite with a sequence of the combination of heat and acid provides a high potential adsorbent for pesticide removal. It also offers a low cost and convenient method when compared with other technics.

Based on the use of artificially prepared pesticide solution in this work the effect of ionic strength on the adsorption was neglected. However, in future work, adsorptions in wastewater effect of ionic strength will be considered.

Supplementary Materials: The following are available online at https:/ / www.mdpi.com/article/10 $.3390 /$ app 11115147/s1, Figure S1: TGA/DTG for bentonite (a), $\mathrm{BA}_{0.5}$ (b), $\mathrm{BC}_{500}$ (c), $\mathrm{BA}_{0.5} \mathrm{C}_{500}$ (d) and $\mathrm{BC}_{500} \mathrm{~A}_{0.5}$ (e); Figure S2: Particle size distributions for bentonite (a), $\mathrm{BA}_{0.5}(\mathrm{~b}), \mathrm{BA}_{0.5} \mathrm{C}_{500}(\mathrm{c}), \mathrm{BC}_{500}(\mathrm{~d})$, and $\mathrm{BC}_{500} \mathrm{~A}_{0.5}$ (e). Figure $\mathrm{S} 3$ : Adsorption isotherm of pesticide on bentonite and modified bentonite at 303, 313 and $323 \mathrm{~K}$. Table S1: Measurement of particle size distribution. Table S2: Thermodynamic parameters for adsorption of atrazine on bentonite and $\mathrm{BC}_{500} \mathrm{~A}_{0.5}$. Table S3: Thermodynamic parameters for adsorption of diuron on bentonite and $\mathrm{BC}_{500}$. Table $\mathrm{S} 4$ : Thermodynamic parameters for adsorption of 2,4-D on bentonite and $\mathrm{BA}_{0.5} \mathrm{C}_{500}$. Table S5: Thermodynamic parameters for adsorption of paraquat on bentonite and $\mathrm{BC}_{500}$. Table S6: Kinetic model parameters obtained for the adsorption of atrazine onto bentonite and modified bentonite adsorbents. Table S7: Kinetic model parameters obtained for the adsorption of diuron onto bentonite and modified bentonite adsorbents. Table S8: Kinetic model parameters obtained for the adsorption of 2,4-D onto bentonite and modified bentonite adsorbents. Table S9: Kinetic model parameters obtained for the adsorption of paraquat onto bentonite and modified bentonite adsorbents.

Author Contributions: Conceptualization, K.R. and C.P.; methodology, K.R.; software, C.P..; validation, K.R. and C.P.; formal analysis, K.R. and C.P.; investigation, K.R. and C.P.; resources, K.R. and C.P.; data curation, K.R. and P.C; writing—original draft preparation, K.R. and P.C; writing-review and editing, K.R. and C.P.; visualization, K.R. and C.P.; supervision, K.R.; project administration, K.R. and P.C; funding acquisition, C.P. All authors have read and agreed to the published version of the manuscript.

Funding: This work was supported by research grants to C.P. from the Royal Thai government Science and Technology Ministry Scholarship, National Science and Technology Development Agency (NSTDA).

Acknowledgments: We also thank the Modern and high Precision Scientific Equipment Laboratories, Suranaree University of Technology, Thailand.

Conflicts of Interest: The authors declare no conflict of interest.

\section{References}

1. Amaral, B.D.; de Araujo, J.A.; Peralta-Zamora, P.G.; Nagata, N. Simultaneous determination of atrazine and metabolites (DIA and DEA) in natural water by multivariate electronic spectroscopy. Microchem. J. 2014, 117, 262-267. [CrossRef]

2. Jamil, T.S.; Gad-Allah, T.A.; Ibrahim, H.S.; Saleh, T.S. Adsorption and isothermal models of atrazine by zeolite prepared from Egyptian kaolin. Solid State Sci. 2011, 13, 198-203. [CrossRef] 
3. Leite, M.P.; dos Reis, L.G.T.; Robaina, N.F.; Pacheco, W.F.; Cassella, R.J. Adsorption of paraquat from aqueous medium by Amberlite XAD-2 and XAD-4 resins using dodecylsulfate as counter ion. Chem. Eng. J. 2013, 215-216, 691-698. [CrossRef]

4. Li, K.; Wu, J.Q.; Jiang, L.L.; Shen, L.Z.; Li, J.Y.; He, Z.H.; Wei, P.; Lv, Z.; He, M.F. Developmental toxicity of 2,4dichlorophenoxyacetic acid in zebrafish embryos. Chemosphere 2017, 198, 55-62. [CrossRef] [PubMed]

5. Rao, Y.F.; Chu, W. Degradation of linuron by UV, ozonation, and UV/O 3 processes-Effect of anions and reaction mechanism. J. Hazard. Mater. 2010, 180, 514-523. [CrossRef]

6. Salman, J.M.; Njoku, V.O.; Hameed, B.H. Adsorption of pesticides from aqueous solution onto banana stalk activated carbon. Chem. Eng. J. 2011, 174, 41-48. [CrossRef]

7. Tomkins, B.A.; Ilgner, R.H. Determination of atrazine and four organophosphorus pesticides in ground water using solid phase microextraction (SPME) followed by gas chromatography with selected-ion monitoring. J. Chromatogr. A 2002, 972, 183-194. [CrossRef]

8. Castro, C.S.; Guerreiro, M.C.; Goncalves, M.; Oliveira, L.C.A.; Anastacio, A.S. Activated carbon/iron oxide composites for the removal of atrazine from aqueous medium. J. Hazard. Mater. 2009, 164, 609-614. [CrossRef]

9. Chen, G.C.; Shan, X.Q.; Zhou, Y.Q.; Shen, X.E.; Huang, H.L.; Khan, S.U. Adsorption kinetics, isotherms and thermodynamics of atrazine on surface oxidized multiwalled carbon nanotube. J. Hazard. Mater. 2009, 169, 912-918. [CrossRef]

10. Kovaios, I.D.; Paraskeva, C.A.; Koutsoukos, P.G. Adsorption of atrazine from aqueous electrolyte solutions on humic acid and silica. J. Colloid Interface Sci. 2011, 356, 277-285. [CrossRef] [PubMed]

11. Salvestrini, S.; Sagliano, P.; Iovino, P.; Capasso, S.; Colella, C. Atrazine adsorption by acid-activated zeolite-rich tuffs. Appl. Clay Sci. 2010, 49, 330-335. [CrossRef]

12. Zadaka, D.; Nir, S.; Radian, A.; Mishael, Y.G. Atrazine removal from water by polycation-clay composites: Effect of dissolved organic matter and comparison to activated carbon. Water Res. 2009, 43, 677-683. [CrossRef]

13. Zhang, C.; Yan, J.; Zhang, C.; Yang, Z. Enhanced adsorption of atrazine from aqueous solution by molecularly imprinted TiO 2 film. Solid State Sci. 2012, 14, 777-781. [CrossRef]

14. Miricioiu, M.G.; Niculescu, V.-C. Fly Ash, from Recycling to Potential Raw Material for Mesoporous Silica Synthesis. Nanomaterials 2020, 10, 474. [CrossRef]

15. Choo, K.Y.; Bai, K. The effect of the mineralogical composition of various bentonites on CEC values determined by three different analytical methods. Appl. Clay Sci. 2016, 126, 153-159. [CrossRef]

16. Murray, H.H. Chapter 2 Structure and Composition of the Clay Minerals and their Physical and Chemical Properties. Dev. Clay Sci. Elsevier 2006, 2, 7-31. [CrossRef]

17. Park, J.-H.; Shin, H.-J.; Kim, M.-H.; Kim, J.-S.; Kang, N.; Lee, J.-Y.; Kim, K.-T.; Lee, J.-I.; Kim, D.-D. Application of montmorillonite in bentonite as a pharmaceutical excipient in drug delivery systems. J. Pharm. Investig. 2016, 46, 363-375. [CrossRef]

18. Slaný, M.; Jankovič, L.; Madejová, J. Structural characterization of organo-montmorillonites prepared from a series of primary alkylamines salts: Mid-IR and near-IR study. Appl. Clay Sci. 2019, 176, 11-20. [CrossRef]

19. Tong, D.S.; Zheng, Y.M.; Yu, W.H.; Wu, L.M.; Zhou, C.H. Catalytic cracking of rosin over acid-activated montmorillonite catalysts. Appl. Clay Sci. 2014, 100, 123-128. [CrossRef]

20. Gates, W.P.; Anderson, J.S.; Raven, M.D.; Churchman, G.J. Mineralogy of a bentonite from Miles, Queensland, Australia and characterisation of its acid activation products. Appl. Clay Sci. 2002, 20, 189-197. [CrossRef]

21. Bieseki, L.; Treichel, H.; Araujo, A.S.; Pergher, S.B.C. Porous materials obtained by acid treatment processing followed by pillaring of montmorillonite clays. Appl. Clay Sci. 2013, 85, 46-52. [CrossRef]

22. Pentrák, M.; Czímerová, A.; Madejová, J.; Komadel, P. Changes in layer charge of clay minerals upon acid treatment as obtained from their interactions with methylene blue. Appl. Clay Sci. 2012, 55, 100-107. [CrossRef]

23. Bojemueller, E.; Nennemann, A.; Lagaly, G. Enhanced pesticide adsorption by thermally modified bentonites. Appl. Clay Sci. 2001, 18, 277-284. [CrossRef]

24. Maqueda, C.; dos Santos Afonso, M.; Morillo, E.; Torres Sánchez, R.M.; Perez-Sayago, M.; Undabeytia, T. Adsorption of diuron on mechanically and thermally treated montmorillonite and sepiolite. Appl. Clay Sci. 2013, 72, 175-183. [CrossRef]

25. Komadel, P. Acid activated clays: Materials in continuous demand. Appl. Clay Sci. 2016, 131, 84-99. [CrossRef]

26. Komadel, P.; Madejová, J. Chapter 7.1 Acid Activation of Clay Minerals. Dev. Clay Sci. Elsevier 2006, 1, 263-287. [CrossRef]

27. Gupta, V.K.; Sharma, M.; Vyas, R.K. Hydrothermal modification and characterization of bentonite for reactive adsorption of methylene blue: An ESI-MS study. J. Environ. Chem. Eng. 2015, 3, 2172-2179. [CrossRef]

28. Heller-Kallai, L. Chapter 7.2 Thermally Modified Clay Minerals. Dev. Clay Sci. Elsevier 2006, 289-308. [CrossRef]

29. Nones, J.; Nones, J.; Riella, H.G.; Poli, A.; Trentin, A.G.; Kuhnen, N.C. Thermal treatment of bentonite reduces aflatoxin b1 adsorption and affects stem cell death. Mater. Sci. Eng. C 2015, 55, 530-537. [CrossRef] [PubMed]

30. $\mathrm{Wu}, \mathrm{P} . ; \mathrm{Wu}, \mathrm{H} . ; \mathrm{Li}, \mathrm{R}$. The microstructural study of thermal treatment montmorillonite from Heping, China. Spectrochim. Acta A. 2005, 61, 3020-3025. [CrossRef]

31. Chorom, M.; Rengasamy, P. Effect of heating on swelling and dispersion of different cationin forms of a smectite. Clays Clay Miner. 1996, 44, 783-790. [CrossRef]

32. Lee, S.Y.; Kim, S.J. Expansion characteristics of organoclay as a precursor to nanocomposites. Colloids Surf. A 2002, 211, 19-26. [CrossRef] 
33. Boudiaf, H.; Boutahala, M.; Sahnoun, S.; Tiar, C.; Gomri, F. Adsorption characteristics, isotherm, kinetics, and diffusion of modified natural bentonite for removing the 2,4,5-trichlorophenol. Appl. Clay Sci. 2014, 90, 81-87. [CrossRef]

34. Olalekan, S.T.; Qudsieh, I.Y.; Kabbashi, N.A.; Alkhatib, M.A.; Muyibi, S.A.; Yusof, F.; Shah, Q.H. Effect of modification on the physicochemical and thermal properties of organophilic clay modified with octadecylamine. Int. J. Eng. Tech. IJET IJENS. 2010, 10, 27-35.

35. Komadel, P.; Madejová, J. Acid Activation of Clay Minerals. Dev. Clay Sci. Elsevier 2013, 5, 385-409.

36. Alver, B.E.; Alver, Ö. The investigation of the effect of thermal treatment on bentonites from Turkey with Fourier transform infrared and solid state nuclear magnetic resonance spectroscopic methods. Spectrochim. Acta A 2012, 94, 331-333. [CrossRef] [PubMed]

37. Brus, J.; Kobera, L.; Schoefberger, W.; Urbanová, M.; Klein, P.; Sazama, P.; Tabor, E.; Sklenak, S.; Fishchuk, A.V.; Dědeček, J. Structure of framework aluminum Lewis sites and perturbed aluminum atoms in zeolites as determined by $27 \mathrm{Al}\{1 \mathrm{H}\} \mathrm{REDOR}$ (3Q) MAS NMR spectroscopy and DFT/molecular mechanics. Angew. Chem. 2015, 54, 541-545.

38. Takahashi, T.; Ohkubo, T.; Suzuki, K.; Ikeda, Y. High resolution solid-state NMR studies on dissolution and alteration of Na-montmorillonite under highly alkaline conditions. Microporous Mesoporous Mater. 2007, 106, 284-297. [CrossRef]

39. Calvet, R.; Prost, R. Cation migration into empty octahedral sites and surface properties of clays. Clays Clay Miner. 1971, 19, 175-186. [CrossRef]

40. Au, P.-I.; Leong, Y.-K. Rheological and zetapotential behaviour of kaolin and bentonite composite slurries. Colloids Surf. A Physicochem. Eng. Asp. 2013, 436, 530-541. [CrossRef]

41. Moradi, S.E. Microwave assisted preparation of sodium dodecyl sulphate (SDS) modified ordered nanoporous carbon and its adsorption for MB dye. J. Ind. Eng. Chem. 2014, 20, 208-215. [CrossRef]

42. Nejati, K.; Davary, S.; Saati, M. Study of 2,4-dichlorophenoxyacetic acid (2,4-D) removal by Cu-Fe-layered double hydroxide from aqueous solution. Appl. Surf. Sci. 2013, 280, 67-73. [CrossRef]

43. Nithaya, K.M.; Arnepalli, D.N.; Gandhi, S.R. In Proccedings of the 6th International Congress on Environmental Geotechnics, New Delhi, India, 8-12 November 2010.

44. Ding, L.; Lu, X.; Deng, H.; Zhang, X. Adsorptive Removal of 2,4-Dichlorophenoxyacetic Acid (2,4-D) from Aqueous Solutions Using MIEX Resin. Ind. Eng. Chem. Res. 2012, 51, 11226-11235. [CrossRef]

45. Bouras, O.; Bollinger, J.-C.; Baudu, M.; Khalaf, H. Adsorption of diuron and its degradation products from aqueous solution by surfactant-modified pillared clays. Appl. Clay Sci. 2007, 37, 240-250. [CrossRef]

46. Ng, C.; Losso, J.N. Freundlich adsorption isotherms of agricultural by-product-based powdered activated carbons in a geosminwater system. Bioresour. Technol. 2002, 85, 131-135. [CrossRef]

47. Yuh-Shan, H. Citation review of Lagergren kinetic rate equation on adsorption reactions. Scientometrics 2004, 59, 171-177. [CrossRef]

48. Ho, Y.S.; McKay, G. Pseudo-Second Order Model for Sorption Processes. Process Biochem. 1999, 34, 451-465. [CrossRef]

49. Ali, I.; ALOthman, Z.A.; Warthan, A. Sorption, kinetics and thermodynamics studies of atrazine herbicide removal from water using iron nano-composite material. Int. J. Environ. Sci. Technol. 2016, 13, 733-742. [CrossRef]

50. Cansado, P.T.T.; Mourão, P.A.M.; Gomes, J.A.F.L.; Almodôvar, V. Adsorption of MCPA, 2,4-D and diuron onto activated carbons from wood composites. Ciência Tecnol. Mater. 2017, 29, e224-e228. [CrossRef]

51. Liu, W.; Yang, Q.; Yang, Z.; Wang, W. Adsorption of 2,4-D on magnetic graphene and mechanism study. Colloids Surf. A Physicochem. Eng. Asp. 2016, 509, 367-375. [CrossRef]

52. Tsai, W.T.; Hsien, K.J.; Chang, Y.M.; Lo, C.C. Removal of herbicide paraquat from an aqueous solution by adsorption onto spent and treated diatomaceous earth. Bioresour. Technol. 2005, 96, 657-663. [CrossRef] [PubMed] 